\title{
Experimental models for dynamic compartmentalization of biomolecules in liquid organelles: Reversible formation and partitioning in aqueous biphasic systems
}

\author{
William M. Aumiller Jr. and Christine D. Keating*
}

\begin{abstract}
Living cells contain numerous subcellular compartments, many of which lack membranous boundaries and are thought to occur due to liquid-liquid phase coexistence. This review will introduce these biological membraneless organelles and discuss simple experimental models based on liquid-liquid phase separation in polymer solutions. When more than one phase is present, solutes such as proteins or nucleic acids can be compartmentalized by partitioning into one of the phases. This could confer benefits to the cell such as enhanced reaction rates or sequestration of toxic molecules. Liquid-like compartments inside living cells are often dynamic, for example appearing and disappearing in response to stimuli and/or at different points in the cell cycle. We will discuss mechanisms by which phase transitions can be induced in the laboratory and inside living cells, with special emphasis on regulating phase formation by phosphorylation state. This work is motivated by a desire to understand the physical and chemical mechanisms that underlie biological processes and to enable new nonbiological applications.
\end{abstract}




\section{Graphical abstract}

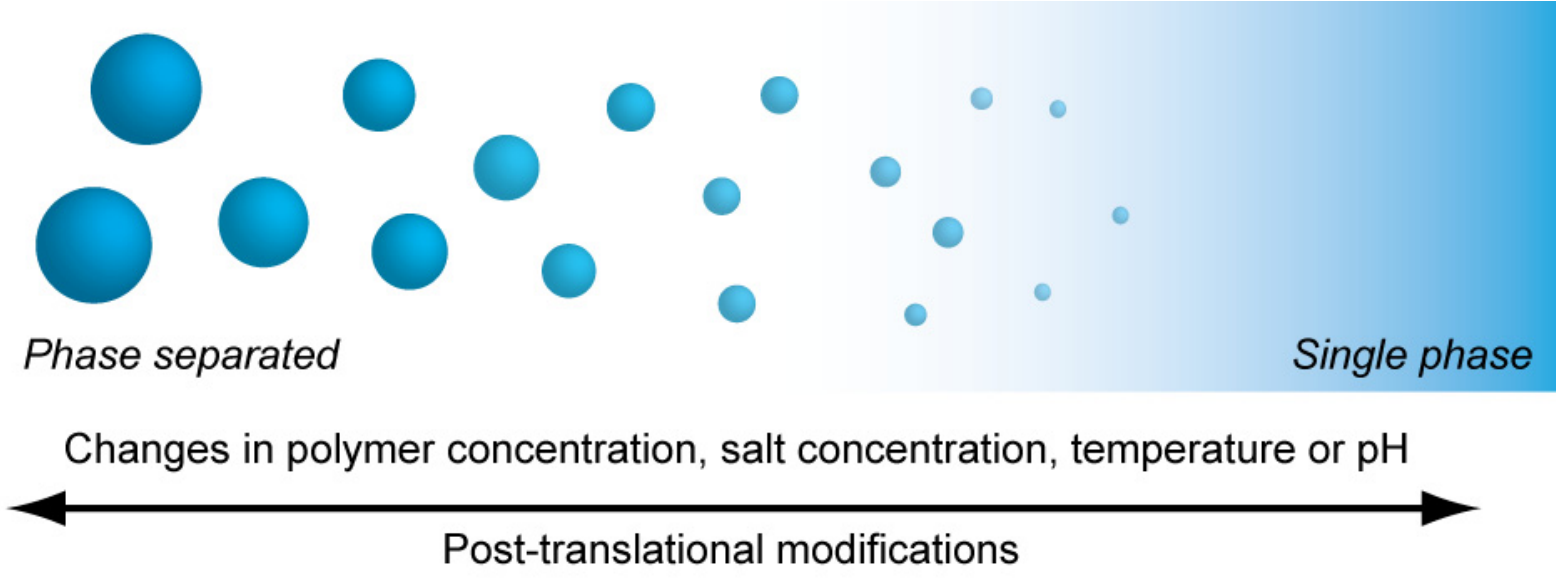

\section{Five Keywords for indexing}

Aqueous two-phase system

Coacervate

Intrinsically disordered protein

Droplet

Phosphorylation

\section{Outline}

1.Introduction

1.Intracellular compartments can be membrane-bounded or membraneless

2.Brief introduction to phase separation in aqueous polymer solutions

3. The role of interface tension in phase behavior.

2. Solute partitioning and its consequences 
2.1 Partitioning as a means of compartmentalization

\subsection{Consequences of partitioning}

3. Dynamic phase separation and compartmentalization in vitro and in vivo

3.1 Reversible compartmentalization initiated by changes to the solution conditions

3.1.1 Thermal phase transitions

3.1.2 Salt-induced phase transitions

3.1.3 $\mathrm{pH}$-driven phase transitions

3.2. Reversible compartmentalization initiated by changes in macromolecule concentration

3.3 Reversible compartmentalization initiated by post-translational modifications of proteins

3.3.1 Phosphoregulation of coacervate formation

3.3.2 Other post-translational modifications

4. Concluding thoughts

\section{Introduction}

It is becoming increasingly clear that the soft matter properties of the intracellular milieu are important to understanding its biological functions $[1,2]$. Our particular interest is dynamic localization of molecules and reactions within subcellular compartments. Recent work suggests that the cytoplasm and nucleoplasm, both of which are crowded with macromolecules, contain multiple coexisting liquid phases of distinct composition [3, 4]. The physicochemical properties of biomacromolecules can lead to phase separation by multiple mechanisms based on, for example, the charge state or hydrophobicity of the molecules and/or specific biorecognition motifs. Partitioning of solutes between coexisting phases drives intracellular compartmentalization. Inspired by biological compartmentalization and its importance for cellular functions including the organization of metabolic processes, researchers have begun to focus on aqueous phase separating model systems as a means to dynamically organize solution 
composition and reactivity [5-14]. This review will introduce readers to subcellular membraneless organelles formed by liquid-liquid phase coexistence and will then discuss simple model systems in which key features of these organelles are reproduced. We will focus on solute partitioning as a mechanism for localization and how this compartmentalization can be changed in response to an external cue (e.g., temperature, dilution) or a change in molecular structure (e.g., protonation state or post-translational modification (PTM)). Solute localization can be used to control reaction location and/or rate; hence this work is important both as a means of learning about biophysical mechanisms for reaction control and as a route to new biotechnologies that take advantage of this control in simpler, nonliving systems.

\subsection{Intracellular compartments can be membrane- bounded or membraneless}

The interior of all living cells is compartmentalized, with concentrations of ions, molecules and multimolecular complexes nonuniformly distributed $[15,16]$. For example, even simple E. coli cells display segregation of condensed DNA from ribosomes within the intracellular volume $[17,18]$. The larger and more complex cells of plants and animals contain well-known membrane-delimited organelles such as the nucleus and mitochondria. In recent years, scientists have begun to appreciate that, in addition to membrane-bounded organelles, other structures that lack membranous boundaries and are often dynamic in their composition, appearance, and location are common. These membraneless organelles, which occur both in the nucleus and in the cytoplasm, are generally rich in proteins and nucleic acids; different types are identified by their distinct compositions (Figure 1). 

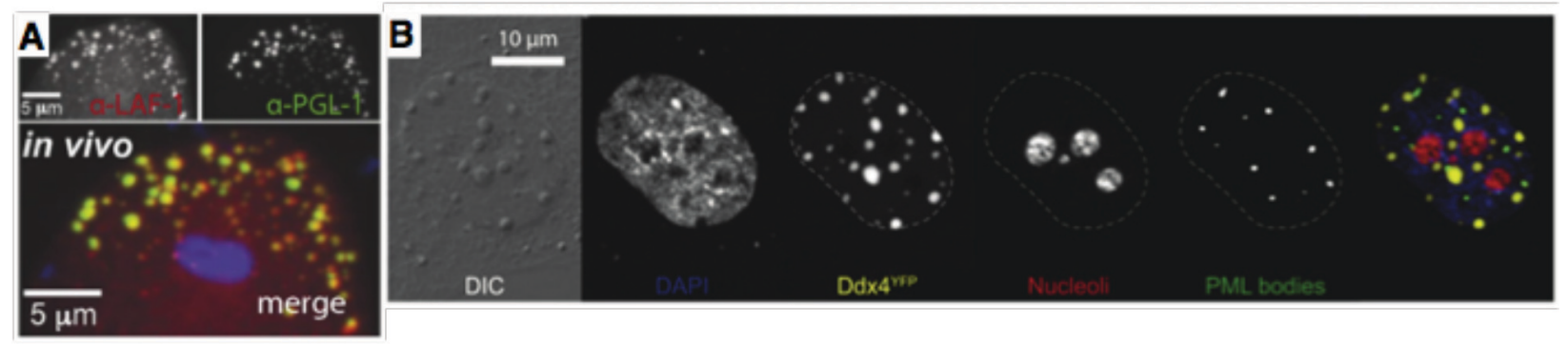

Figure 1. Recent examples of membraneless organelles in cytoplasm and nucleoplasm. (A) Confocal images of $\mathrm{P}$ granules in $C$. elegans, immunostained for LAF-1 protein and PGL-1 proteins. The nucleus is DAPI stained in blue in the bottom image. Reproduced with permission from [19] (B) Differential interference contrast (DIC) image and fluorescence images of a HeLa cell, with stained membraneless organelles. The nucleus is blue, nucleoli in red, PML bodies in green. The yellow droplets are artificial liquid organelles, composed of a variant of Ddx4 that contains yellow fluorescent protein (YFP). Reproduced with permission from reference [20].

Many membraneless organelles are thought to form by liquid/liquid phase separation (LLPS): "liquid organelles." Hyman, Brangwynne and coworkers identified liquid-like behavior in an intracellular compartment in 2009 , by analyzing the spatiotemporal distribution of fluorescently-labeled compartments [21]. They found that $\mathrm{P}$ granules from the nematode worm C. elegans displayed liquid flow in the cytoplasm, as well as dripping and wetting around the nucleus (Figure 2A). Individual P granule compartments fused to form larger compartments, and the contents of the compartments underwent rapid diffusion, which indicates a highly dynamic structure. Another prominent early example of a liquid organelle is the nucleoli of Xenopus laevis ooctyes (Figure 2B). These structures underwent fusion and fission events, showed spherical shapes at equilibrium, and had a "pinching-off" behavior that is characteristic of viscous liquids [22]. Since these early examples, a number of other liquid-like organelles have been identified. Additionally, phase behavior of components isolated from or inspired by biopolymers found in these liquid organelles have been studied in vitro. Several recent representative examples of 
these biological and biomimetic liquid droplet-forming systems are summarized in Table 1. In addition to these structures, many other membraneless organelles have been identified, including: Cajal bodies, nuclear speckles, paraspeckles, Promyelocytic Leukemia (PML) bodies in the nucleoplasm and other cytoplasmic bodies such as stress granules and germ granules, which are reviewed elsewhere $[3,4,23]$. In many cases these membraneless organelles are also thought to form by LLPS [4].
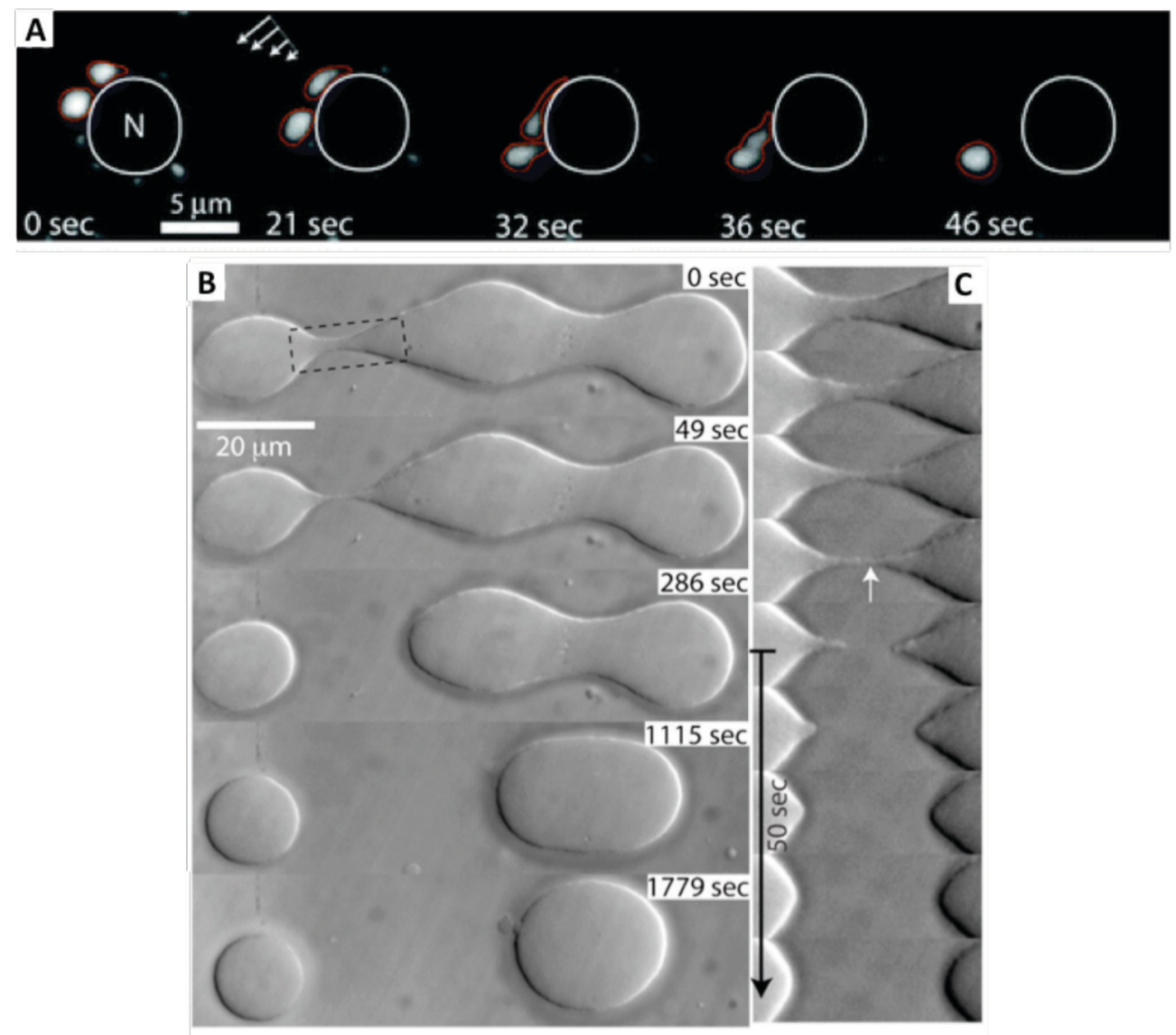

Figure 2. "Liquid organelles" observed in vivo. (A) P granules in Caenorhabditis elegans appear to flow and show dripping around the nucleus, "N" as well as fusion/coalescence at later times. (B) Nucleoli from Xenopus laevis oocytes have a "pinching off" behavior (within dashed line) while other undergo fusion to form a nearly spherical droplet. (C) The pinching off behavior is highlighted. Panel A is reproduced from reference [21] with permission from AAAS. Panels B and $\mathrm{C}$ are reproduced from reference [22] with permission from the National Academy of Sciences, USA. 
Table 1: Liquid droplet forming structures related to membraneless organelles and their key properties

\begin{tabular}{|c|c|c|c|}
\hline $\begin{array}{l}\text { Liquid droplet forming } \\
\text { structure and/or phase } \\
\text { forming component(s) }\end{array}$ & $\begin{array}{l}\text { D i d l i q u i d } \\
\text { compartments } \\
\text { form in vivo } \\
\text { or in vitro? }\end{array}$ & Key finding(s) & Reference \\
\hline $\begin{array}{l}\text { Nucleolus in Xenopus } \\
\text { laevis oocytes }\end{array}$ & In vivo & $\begin{array}{l}\text { The nucleoli behave as liquid } \\
\text { droplets }\end{array}$ & {$[22]$} \\
\hline $\begin{array}{l}\mathrm{P} \text { granules from } C . \\
\text { elegans, with the protein } \\
\text { component LAF-1, a } \\
\text { DDX3 family RNA } \\
\text { helicase }\end{array}$ & both & $\begin{array}{l}\text { IDRs of the protein LAF-1 are } \\
\text { key determinants for formation of } \\
\text { phases } \\
\text { Addition of RNA fluidized the } \\
\text { droplets }\end{array}$ & {$[19]$} \\
\hline $\begin{array}{l}\text { Nucleoli from C. } \\
\text { elegans with the protein } \\
\text { component FIB-1, } \\
\text { which contains IDRs }\end{array}$ & both & $\begin{array}{l}\text { Phase transition is protein } \\
\text { concentration and rRNA } \\
\text { concentration dependent } \\
\text { Classical phase separation } \\
\text { mechanics (nucleation, growth, } \\
\text { coarsening) are consistent with in } \\
\text { vivo droplet behavior }\end{array}$ & {$[24]$} \\
\hline $\begin{array}{l}\text { Multivalent signaling } \\
\text { proteins domains SRC } \\
\text { homology } 3 \text { (SH3) and } \\
\text { proline-rich motif } \\
\text { (PRM) and the related } 3 \\
\text { component system } \\
\text { nephrin, NCK, and N- } \\
\text { WASP }\end{array}$ & both & $\begin{array}{l}\text { Multivalency drove phase } \\
\text { separation } \\
\text { Phosphorylation of the nephrin } \\
\text { component lowered the } \\
\text { concentration needed for phase } \\
\text { separation }\end{array}$ & {$[25]$} \\
\hline $\begin{array}{l}\text { Stress granules } \\
\text { containing the protein } \\
\text { kinase DYRK3 }\end{array}$ & In vivo & $\begin{array}{l}\text { The activity of DYRK3 kinase } \\
\text { promoted disassembly of the } \\
\text { stress granules. } \\
\text { DYRK3 contains a LCS region } \\
\mathrm{N} \text { terminal domain of DYRK3 } \\
\text { promotes stress granule formation } \\
\text { in its inactive form }\end{array}$ & [26] \\
\hline
\end{tabular}




\begin{tabular}{|c|c|c|c|}
\hline $\begin{array}{l}\text { M e } \mathrm{m} \text { b r a } \mathrm{n} \text { e } 1 \text { e } \mathrm{s} \mathrm{s} \\
\text { organelles composed of } \\
\text { a } \mathrm{DDx} 4 \text { variant. }\end{array}$ & both & $\begin{array}{l}\text { Droplet formation was sensitive to } \\
\text { temperature, ionic strength, } \\
\text { concentration, and arginine } \\
\text { methylation. }\end{array}$ & [20] \\
\hline $\begin{array}{l}\text { Stress granules } \\
\text { containing the RNA } \\
\text { binding protein } \\
\text { hnRNPAl }\end{array}$ & both & $\begin{array}{l}\text { Low temperature, low salt, } \\
\text { increased concentration, crowding } \\
\text { agents (PEG, Ficoll), and bound } \\
\text { RNA promoted phase separation } \\
\text { LCS of the hnRNPA1 was key } \\
\text { determinant of phase separation } \\
\text { Multivalency promoted phase } \\
\text { separation }\end{array}$ & [27] \\
\hline $\begin{array}{l}\text { Six IDPs with sequences } \\
\text { b a s e d o n known } \\
\text { components of RNP } \\
\text { granules and the granule } \\
\text { protein hnRNPA1 }\end{array}$ & In vitro & $\begin{array}{l}\text { Low salt and presence of RNA } \\
\text { promoted phase separation. }\end{array}$ & {$[28]$} \\
\hline $\begin{array}{l}\text { Nucleic acid mimicking } \\
\text { polymer poly (ADP } \\
\text { ribose) (PAR) with IDPs } \\
\text { containing arginine- } \\
\text { glycine-glycine (RGG) } \\
\text { regions }\end{array}$ & both & $\begin{array}{l}\text { PAR acts as a nucleation site for } \\
\text { LCS proteins to assemble } \\
\text { Electrostatic interactions between } \\
\text { PAR and RGG d o m a ins } \\
\text { determined phase separation } \\
\text { Assembly occurs at site of DNA } \\
\text { damage presumably to facilitate } \\
\text { DNA repair. }\end{array}$ & [29] \\
\hline $\begin{array}{l}\text { Disordered protein } \\
\text { Whi3, containing a } \\
\text { poly-glutamine (polyQ) } \\
\text { domain and RRM motif } \\
\text { and mRNA binding and } \\
\text { CLN3 mRNA }\end{array}$ & In vitro & $\begin{array}{l}\text { Whi3 can phase separate on its } \\
\text { own. CLN3 promotes phase } \\
\text { separation at physiological } \\
\text { conditions } \\
\text { RNA to protein ratio is critical in } \\
\text { determining size and quantity of } \\
\text { droplets }\end{array}$ & {$[30]$} \\
\hline
\end{tabular}




\begin{tabular}{|c|c|c|c|}
\hline $\begin{array}{l}\text { RNA binding protein } \\
\text { F US (F us ed in } \\
\text { sarcoma) that is } \\
\text { associated with the } \\
\text { neurodegenerative } \\
\text { dis ease A L S } \\
\text { (Amyotrophic Lateral } \\
\text { Sclerosis) and enriched } \\
\text { in the nucleus }\end{array}$ & both & $\begin{array}{l}\text { FUS contains LCDs and forms } \\
\text { liquid droplets } \\
\text { In vivo, the liquid compartments } \\
\text { composed of FUS form in } \\
\text { response to cellular stress (sites of } \\
\text { DNA damage) } \\
\text { In vitro, as the droplets age, they } \\
\text { form solid aggregate structures } \\
\text { (aberrant phase separation) }\end{array}$ & [31] \\
\hline
\end{tabular}

\subsection{Brief introduction to phase separation in aqueous polymer solutions.}

Liquid-liquid phase coexistence is common in aqueous solutions of one or more polymeric solutes. Mechanisms for LLPS depend upon the identity of the polymeric solutes, with phase coexistence possible in solutions of either associating or non-associating polymers [5, 32-36]. Here, we briefly consider two instructive limiting types of aqueous phase separation that are particularly relevant to intracellular phase separation: complex coacervation of oppositelycharged polyelectrolytes and neutral polymer/polymer phase separation.

Associative phase separation, in which one or more polymers becomes concentrated into a dense, polymer-rich phase and the other phase is depleted in polymers, is often called coacervation. The polymer-rich coacervate phase often exists as dispersed droplets surrounded by the dilute continuous phase. Complex coacervation occurs when the associative phase separation process involves oppositely charged polyelectrolytes. Thermodynamically, the driving force for complex coacervation is the increase in entropy of the system caused by the release of 
the small hydrated counterions from ion pairing of the polyelectrolytes $[33,37]$. One of the earliest pioneers in the field of coacervation was H. G. Bungenberg de Jong who coined the term complex coacervation to describe the phase behavior of biological polyelectrolytes, such as gelatin and gum Arabic [38]. Since then, many other coacervate systems composed of biological polyelectrolytes including proteins, polypeptides, polysaccharides, and nucleic acids [39-44] as well as synthetic polyelectrolytes $[45,46]$ have been reported. Many factors influence the coacervation process, such as the strength of the electrostatic interaction, the size of the polyelectrolytes, the charge density, the $\mathrm{pH}$, and salt concentration [43]. These effects will be explored in more detail below. Although complex coacervation has been a particular focus of research in synthetic systems and observations of salt dependence point to its importance for biological phase-forming proteins, not all associative phase separation requires ion complexation. Other types of associations between macromolecules of the same or different types can result in a concentrated droplet phase surrounded by a dilute continuous phase [32, 36, 47]. These include scenarios in which a single polymer can undergo phase separation in response to changes in solvation, solution temperature or salt/small molecule concentration [35].

The other major class of phase separation most relevant to liquid phase separation in biology is non-associative phase separation, which generally involves uncharged polymers. In this literature, solutions that undergo non-associative phase separation are commonly termed aqueous two-phase systems (ATPS). At a high enough weight percent (generally higher than the weight percent required for coacervation), structurally dissimilar polymers will phase separate to form a two or more phase system where each phase is enriched in one of the polymers, and all of phases are crowded with macromolecules. The quintessential example of neutral polymer phase 
separation is the polyethylene glycol (PEG)/ dextran system, which has been characterized extensively by Albertsson and others [34, 47, 48]. Other systems have been developed to include other polysaccharides and proteins [49]. These ATPS formed from neutral polymers have a long history of use for bioseparations, where they enable biocompatible media for liquid-liquid extraction of biomolecules and organelles [34, 36, 47, 48]. When more than two non-associating polymers are mixed, aqueous-multiphase systems (AMPS) form. For example, addition of the polysucrose, Ficoll, to a PEG/dextran ATPS results in formation of a third, Ficoll-rich phase between the PEG-rich and dextran-rich phases [50, 51]. This contrasts with the expected outcome of mixing multiple polycations with multiple polyanions in a complex coacervate, where one expects that one coacervate phase rich in all components will form. There have been relatively few physical chemistry studies of complex coacervates that examined the impact of more than two polymeric components. Priftis and coworkers recently reported ternary coacervate systems composed of poly(N,N-dimethylaminoethyl methacrylate) (PDMAEMA) and poly(acrylic acid) (PAA) as the base polycation and polyanion, respectively. The third component was either another polycation poly(allylamine) (PAH) or branched poly(ethylenimine) (PEI). Addition of the third component allowed coacervate formation over a broader range of polymer ratios, and a higher critical salt concentration compared to the binary system [52].

The intracellular environment is of course more complex than either of these limiting examples, and more types of associative and non-associative phase separation can be anticipated. Biomacromolecular solutes are present in high concentrations and can interact with each other through attractive and repulsive interactions due to charges, hydrophobicity, hydrogen bonding, 
and specific biorecognition in addition to changes in solvation and conformation upon association. Membraneless organelles are often associated with one or more intrinsically disordered proteins (IDPs) or proteins with intrinsically disordered regions (IDRs) that lack permanent secondary or tertiary structure, rendering them more flexible than a typical globular protein [53]. The sequences that make up these proteins/regions are referred to as low complexity sequences (LCSs), containing stretches of repeating amino acids. The amino acids involved are often polar (glycine [G], glutamine [Q], asparagine [N], serine [S]), positively charged (arginine $[R]$ and lysine $[K]$ ), negatively charged (aspartic acid [D] and glutamic acid [E]) or aromatic (phenylalanine [F] and tyrosine [Y]) [54]. Such repeats provide a route to multivalent interactions; the concentration necessary for phase separation can be lowered by introducing more repeat units in the protein sequence $[25,55]$. This is consistent with expectations based on synthetic polymer systems, where increased polyion length results in a decreased threshold concentration for phase separation and stronger electrostatic interaction (evidenced by an increase in critical salt concentration). [56]. Pure solutions of these IDPs have been shown to undergo phase separation giving rise to a protein-rich droplet phase and protein-poor continuous phase [54]. In vivo, many proteins and RNAs are associated with the membraneless organelles. [54] Numbers can vary widely; for example, P granules are comprised of approximately 40 proteins and at least 6 mRNAs [4,57], while human nucleoli contain approximately 4500 proteins $[4,58]$. One or more macromolecular component is generally required to form the organelle and the others are thought to associate with the structure by tight or weak binding to its components [54] and/or through nonspecific partitioning in response to e.g., differences in solvation or dielectric inside and outside the droplets [20]. In several systems where IDPs phase 
separate alone in vitro, addition of RNA has been shown to promote droplet formation over a wider range of conditions $[27,28,30]$, which also suggests a role for ion pairing interactions and complex coacervation, since RNA is a polyanion.

\subsection{The role of interfacial tension in phase behavior.}

Knowledge of the interfacial tension, $\gamma$, of a phase is useful for predicting the stability of the phase and how it will interact with other phases/surfaces [59]. Polyelectrolyte complex coacervates have low, tunable, $\gamma$ in the range $\sim 1 \times 10^{-3}$ to $\sim 1 \mathrm{mN} / \mathrm{m}[59,60]$, with $\gamma$ depending on polyelectrolyte length and charge density as well as solution ionic strength. The interfacial tension of coacervates increases with increasing chain length [59] and decreases with increasing salt [60]; additionally, strong polyelectrolytes with high charge density have higher $\gamma$ than weak polyelectrolytes [60]. Non-associative systems such as the PEG/dextran ATPS also have tunable interfacial tension values in a similar range $\left(\gamma=0.5 \times 10^{-3}-0.5 \mathrm{mN} / \mathrm{m}\right)[36]$, where the higher values are observed for higher polymer molecular weights [61] and/or polymer concentrations [62]. For nonionic polymer ATPS, unlike complex coacervates, salt concentration is not expected to greatly impact $\gamma$. For comparison, interfacial tensions of some membraneless organelles have been reported to be in the $\sim 1-10 \mu \mathrm{N} / \mathrm{m}$ range $[21,22,63]$, at the lower end of the values for synthetic polymers. Recent work has demonstrated that the core-shell morphology of coexisting, immiscible nucleolar subcompartments arises from differences in interfacial tension of the subcompartments [63]. The variation in surface tension of the nucleoli subcompartments is hypothesized to be due to differences in the sequences of disordered regions of the proteins that make up the compartments and changes in fluidity of the droplets by addition or removal of RNA [63]. 
The reduction of interfacial tension associated with decreased surface area provides a driving force for not only the typical spherical morphology of coacervates and liquid organelles, but also for the coalescence of droplets that represent a dispersed phase. In synthetic polymer systems, coalescence of dispersed phase droplets can be resisted by electrostatic repulsions if the droplets are charged and ionic strength is low, by adherence to a solid support such as a microscope coverslip that prevents droplets from contacting each other, or by adsorbing material at the interface that provides stabilization. Examples of the latter case include formation of Pickering emulsions [64-68] or special copolymers designed to act as surfactants at the aqueous/ aqueous interface [69]. Inside cells, the persistence of multiple copies of various membraneless organelles $[35,70]$ suggests that they are stabilized against coalescence. Some membraneless organelles are associated with specific intracellular locations that may serve as nucleation sites for their assembly; for example, nucleoli form at nucleolar organizing regions containing tandem repeats of rDNA genes [71]. Such attachment sites could also prevent contact and coalescence of the multiple nucleoli within the nucleus. Physical separation by cytoskeleton or other intracellular networks could provide another mechanism for stabilizing intracellular droplets from coalescence. Indeed, disruption of the actin network in Xenopus germinal vesicles results in sedimentation and fusion of membraneless organelles [72]. Recent studies of RNA splicing speckles indicate that their coalescence can be controlled by ATP-dependent motions within the nucleus [73].

\section{Solute partitioning and its consequences}

\subsection{Partitioning as a means of compartmentalization}


Distinct solution environments with different local composition arise upon phase separation. In addition to differences in local concentration of the phase-forming macromolecules themselves, other solutes can accumulate in, or be excluded from, one of the phases by equilibrium partitioning $[5,35]$. In general, surface chemical groups and the size/ surface area of the solute dictate the phase preference and degree of partitioning of solutes in a particular phase system $[7,74]$. For complex coacervates, solute charge plays an important role due to the possibility of solute interactions with polyelectrolytes; charged solutes can compete with like-charged coacervate components for interactions with components of opposite charge [75]. Specific biorecognition interactions, either with the phase-forming components themselves or another solute partitioned there, can increase solute partitioning [74]. Biorecognition is particularly relevant to biological coacervation in membraneless organelles, given the large number of protein-protein and protein-RNA interactions that are present.

Local distributions of proteins, nucleic acids, and small molecules are all important for intracellular functions and hence understanding how these solutes partition in biphasic systems is of interest. In the case of the PEG/dextran system, native proteins usually partition to the dextran-rich phase because of favorable interactions with the more hydrophilic dextran-rich phase [34]. In the case of coacervates, many proteins or peptides will accumulate in the coacervate phase (Figure 3). The degree of partitioning to the coacervate phase is dependent on a number of factors, such as the size and charge of the protein itself, as well as the nature of the coacervate and the solution conditions. It should be noted that solutes can be excluded from the coacervate, such as large, charged proteins with the same sign as the net coacervate charge, as well as charge coated nanoparticles [6]. We demonstrated that negatively-charged protein/peptide 
organelles compartmentalized positively charged peptide to a greater extant than a negatively charged peptide [55].

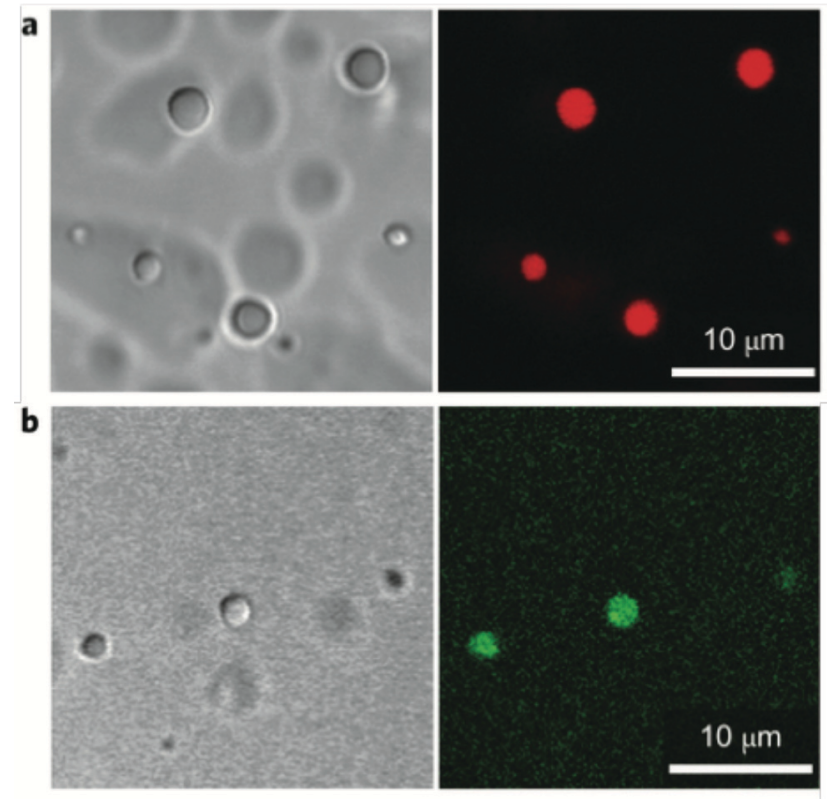

Figure 3 Proteins and peptides can accumulate to coacervate droplets. Both fluorescent peptide (sequence: RRASLRRASL, panel A) and fluorescent protein (protein kinase A, panel B) partition to coacervate droplets composed of poly U/RRASLRRASL. Reproduced with permission from Reference [55].

In addition to peptides and proteins, nucleotides can be highly compartmentalized within aqueous biphasic systems. The length, sequence and structure all influence partitioning of nucleotides, as does the composition of the phase system. In a PEG/dextran system, single stranded RNA typically partitions to the dextran-rich phase, with an increased length resulting in a greater degree of partitioning [14]. RNA can also accumulate to the droplet phase in a coacervate system $[55,75]$. The degree of accumulation of RNA to a coacervate can be sequence dependent due to affinity interactions. In a polyU/peptide complex coacervate system, complementary poly A RNA partitioned more strongly than other sequences of the same size to a 
coacervate composed of poly U [55]. In contrast, neither length nor sequence of RNA influenced the extremely strong partitioning of RNAs into polyallylamine/ATP coacervates (Figure 4A). This can be understood as displacement of ATP molecules by the RNAs, all of which offer substantially greater multivalency of interaction with the polyamine [75]. Droplets composed of a protein $(\mathrm{Ddx} 4)$ associated with intracellular membraneless organelles have been shown to discriminate between single- and double-stranded DNAs. Ddx4 is a primary protein constituent of cytoplasmic droplets referred to as nuage or P granules (in mammals or worms, respectively). Single-stranded DNA (ssDNA) accumulated inside droplets, while double stranded DNA (dsDNA) was excluded (Figure 4B, C). [20]. The ability of the Ddx4 droplets to selectively uptake single-stranded nucleic acids rely on cation-pi and electrostatic interactions that are more favorable for the single-stranded sequences than the less flexible double-stranded sequences, and could be important in the biochemical function of these structures [20,76]. Additionally, when dsDNA was forced into the droplets by incubation with a highly-charged GPF variant that partitions to the droplets, the dsDNA melted [76]. This suggests that for protein-mediated trafficking of nucleic acids is a viable mechanism for changing molecular occupancy inside membraneless organelles [76]. 
A
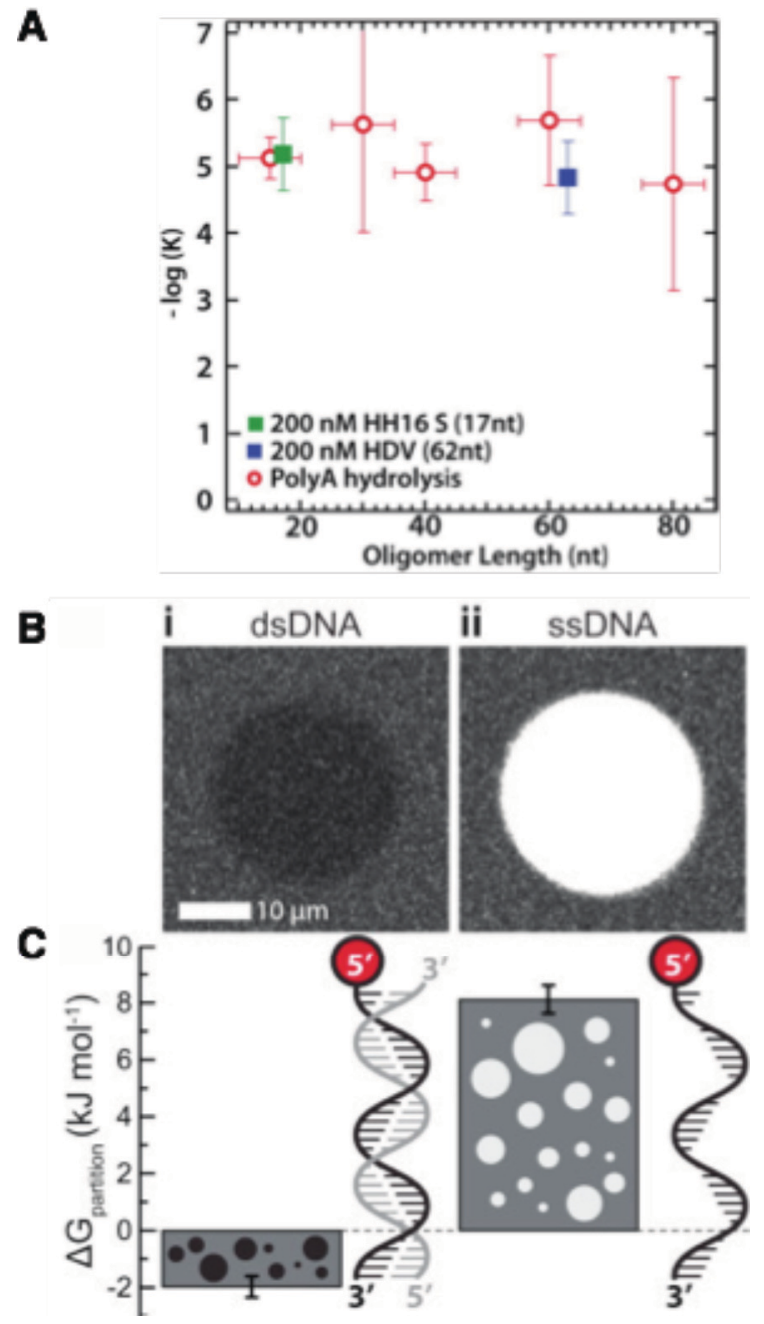

Figure 4. Nucleic acid partitioning. (A) Similarly strong partitioning of different RNA lengths and sequences/secondary structures into polyamine/ATP coacervates. $(B, C) \mathrm{Ddx} 4$ variant liquid organelles and their partitioning of 32 nt DNA. (B) dsDNA was excluded from the droplet (i), while single stranded DNA partitioned to the droplets. (ii) (C) Partitioning coefficients were used to calculate the free energy change. Part A reproduced with permission from [75]. Copyright 2016, American Chemical Society. Part B and C reproduced with permission from reference [20].

Small molecules/ions can also be partitioned in biphasic systems. Due to their small surface area they do not generally partition strongly in neutral polymer ATPS unless affinity polymers are present [34]. Mann and coworkers have demonstrated accumulation of porphyrins and dye molecules in polypeptide/nucleotide coacervate droplets [7, 77]; partitioning coefficients varied with molecular structure, with charge playing a notable role. Extremely high local 
concentrations of ionic small molecules have been achieved when these molecules serve as components in coacervate formation. Complex coacervates composed of poly(allylamine) and nucleotides (AMP, ADP, ATP) had local concentrations of the nucleotides $>1 \mathrm{M}$ when just $\leq 5$ $\mathrm{mM}$ of the nucleotide was added to the bulk. $\mathrm{Mg}^{2+}$ added at $10 \mathrm{mM}$ reached between 1-5 $\mathrm{M}$ within the droplets [75]. Peptide (polylysine, MW=24 kDa)/nucleotide (ATP) coacervates compartmentalized the phase-forming components themselves at a concentration of $1.6 \mathrm{M}$ polylysine and $400 \mathrm{mM}$ ATP [7].

Changes in the conformation of a biomolecule can impact its partitioning. For example, many proteins will accumulate in the dextran-rich phase of a PEG/dextran system in their native, globular forms but to the PEG-rich phase upon denaturation [78]. We have used $\mathrm{pH}$-induced conformational changes to affect the partitioning of several proteins, including human serum albumin (HSA) in artificial cells based on a PEG/dextran ATPS. In a natured state at $\mathrm{pH} 6.5$, the protein partitions to the dextran-rich phase. At $\mathrm{pH} 12.0$, the protein changes conformation to a denatured state and partitions to the PEG-rich phase (Figure 5). In another example, the Ddx4 organelles partitioned nucleic acids differently based on their structure. Structured nucleic acid hairpins partitioned more strongly than over unstructured single-stranded sequences [76]. This observation could be explained by the size of the mesh-like weave of the Ddx4 crowded interior of the organelles; more compact nucleic acids structure are favored over extended or rigid structures [76]. 


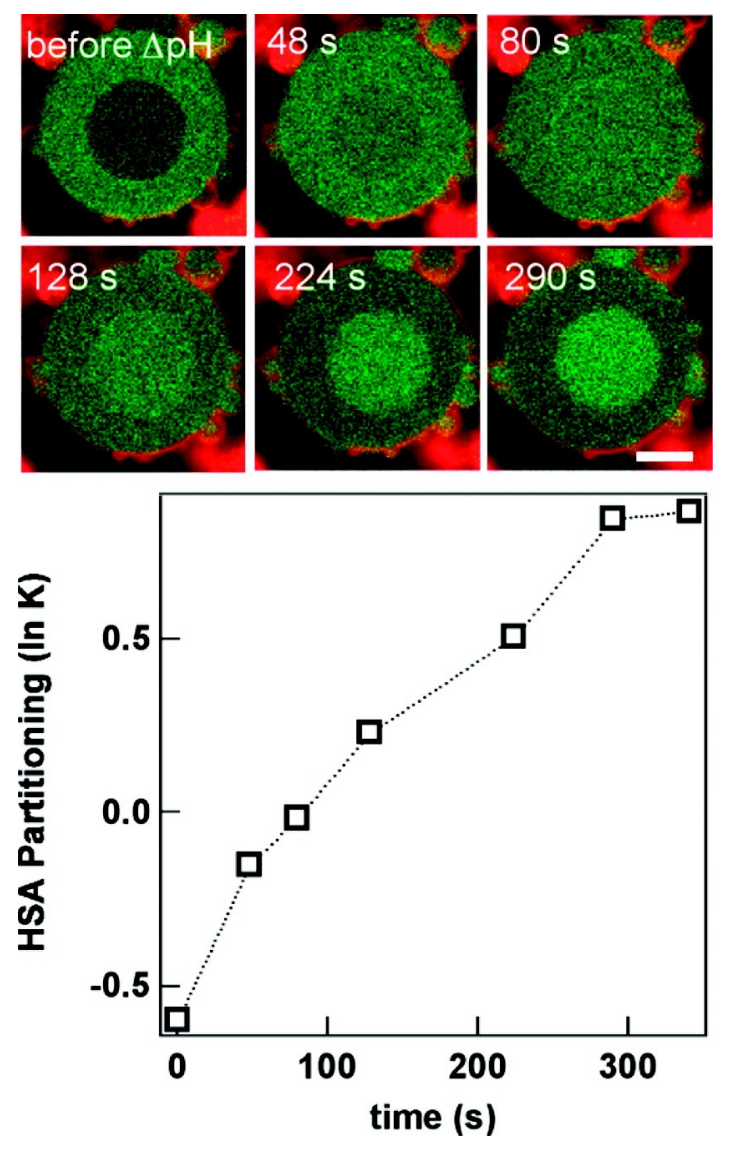

Figure 5. Dynamic changes in protein partitioning in response to changes in $\mathrm{pH}$. Human serum albumin (HSA, green) starts in the dextran-rich phase at $\mathrm{pH} 6.5$ in a lipid vesicle (membrane in red). When the $\mathrm{pH}$ is changed to 12 , the protein conformation changes and partitions to the PEGrich phase. Reproduced with permission from reference [79]. Copyright 2010, American Chemical Society.

Inside cells, changes in protein conformation are generally less extreme than denaturation/renaturation, but are nonetheless a common means of altering subcellular localization. For example, post-translational modifications of proteins such as changes in phosphorylation state often drive conformational changes and alterations in binding affinities and localization $[80,81]$.

\subsection{Consequences of partitioning}


Localization of solutes into droplet phases within the cytoplasm or nucleoplasm of cells is thought to provide one or more advantages to the cell, which may include enhanced reaction rates due to concentration and/or co-localization of reactants, providing a favorable medium for reaction (e.g., local $\mathrm{pH}$ or dielectric constant), or sequestering harmful solutes to prevent cellular damage $[35,82]$. It is widely hypothesized that biochemical pathways involving many sequential reaction steps performed by different enzymes could benefit from colocalization within reactive compartments such as membraneless organelles (Figure 6A) [82]. Co-localization of sequential enzymes by other mechanisms, including assembly onto a scaffold or expressing as bifunctional fusion proteins has led to rate enhancements for some enzyme systems [83-85]. 

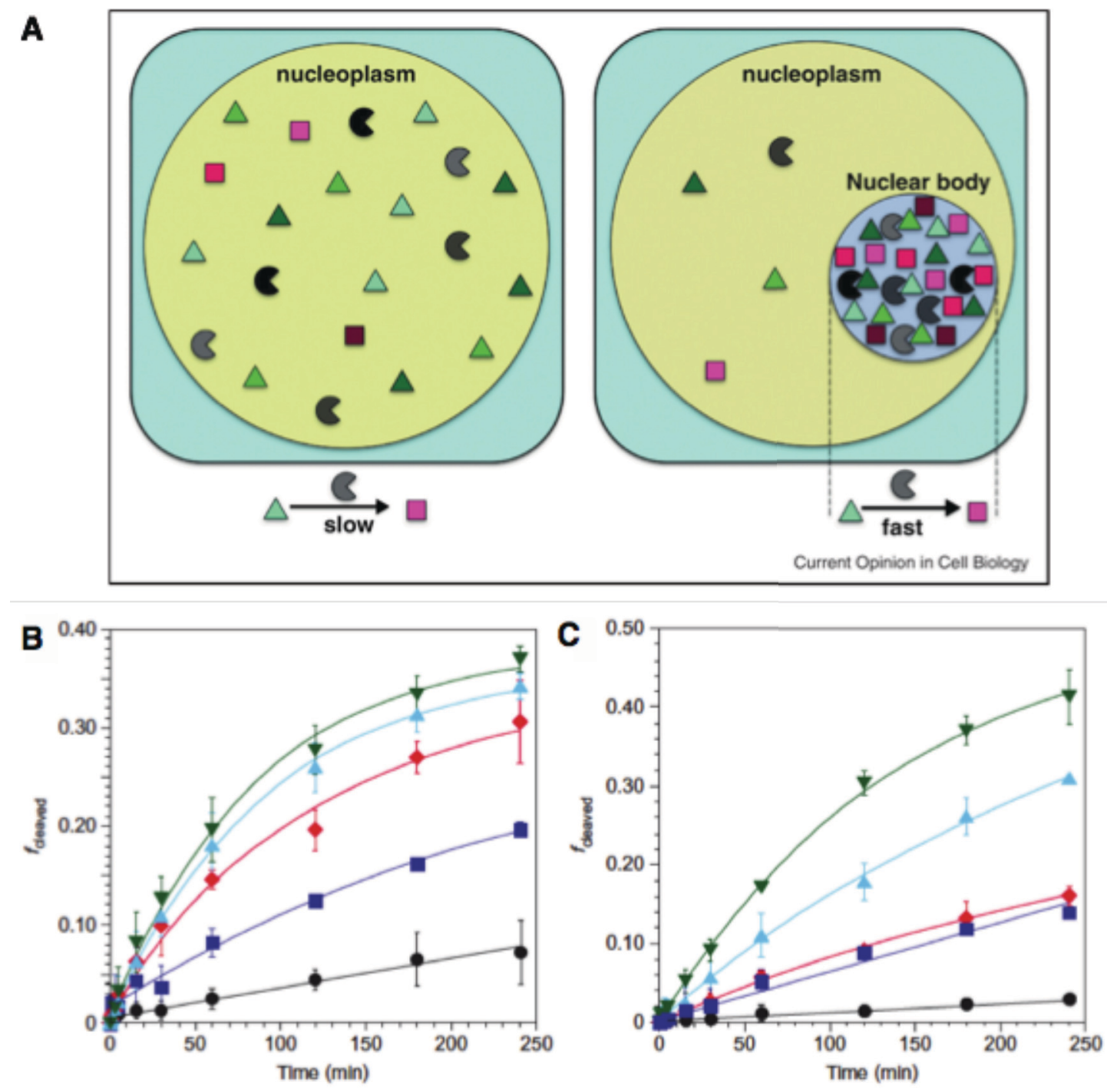

Figure 6. Compartmentalization enhances reaction rates. (A) Schematic showing effect of compartmentalization. When enzymes (Pacmen) are distributed throughout the nucleoplasm, conversion of substrate (triangles) to product (squares) is slow. Colocalization to a liquid nuclear body, however, results in more product formation. (B, C) RNA cleavage rate, illustrated as the fraction of RNA substrate strands cleaved versus time, is enhanced by compartmentalization of

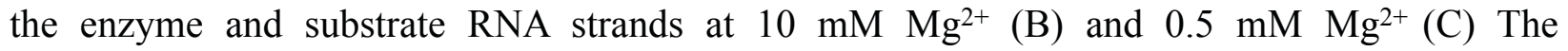
dextran:PEG volume ratios were 1:0 (black circles), 1:5 (blue squares), 1:12.5 (red diamonds), 1:50 (blue triangles), and 1:100 (green inverted triangles). Panel A reproduced with permission from Reference [82]. Panels B and C adapted with permission from Macmillan Publishers Ltd: Nature Chemistry [14], copyright 2012. 
Inspired by the anticipated benefits of reaction localization within a droplet phase, a number of experimental model systems have appeared in which enzymes are partitioned to one of the phases of a two-phase system. In many cases, the rate of a reaction is increased. For example, the rate of an RNA cleavage reaction was enhanced nearly 66-fold when it was partitioned the dextran-rich phase of a PEG/dextran ATPS (Figure 6B,C). The concentration was increased nearly $3000 \times$ by partitioning at a volume ratio of 1:100 (that is, 1 part dextran-rich phase to 100 parts PEG-rich phase) compared to a single, homogeneous phase [14]. In another example, the enzyme urease partitioned relatively weakly to the dextran-rich phase (a factor of $8.3 \mathrm{x}$ ), yet the mineralization reaction catalyzed by this enzyme was almost exclusively within that phase [86]. Furthermore, dextran-rich phase droplets could be stabilized by liposomes to create artificial mineralizing vesicles [87]. Rate enhancements have also been observed within coacervate systems. When the actinorhodin polyketide synthase complex and its substrate were partitioned in a poly(diallyldimethylammonium chloride)/ATP coacervate, the rate was enhanced by a factor of 18 [88]. In another example, the rate of transcription was enhanced nearly 6-fold within phase separated droplets made of cell lysate compared to single-phase controls [9]. The degree of partitioning can impact rates. Enzymes from the purine biosynthesis pathway were compartmentalized to the dextran-rich phase of a PEG/dextran ATPS, but significant rate enhancements could only be observed with strong partitioning (partitioning of a factor of $100 \times$ or greater) [13].

Partitioning can not only enhance rates of reaction by bringing molecules together in the same phase, but also restrict reactions to an interface. In a two phase system composed of PEG and sodium citrate, where a PEG-rich phase and a citrate-rich phase are present, sequential 
enzymes glucose oxidase and horseradish peroxidase (HRP) were partitioned to the citrate-rich phase. The cofactor for HRP, Amplex Red, was partitioned strongly to the PEG-rich phase, and as a result, the reaction primarily occurred at the interface [12].

It is important to note that the reaction medium is different in the two phases, which will impact reaction rates and cannot usually be predicted by changes in local concentration alone, even when local concentrations of all relevant molecules are known. Excluded volume effects from the high concentrations of background macromolecules can, for example, alter protein folding and multimerization state $[89,90]$. Chemical effects from other solutes or local solvent environment can impact, for example, binding site accessibility [91, 92]. The situation becomes more complex as increasing numbers of biochemical substrates, enzymes, intermediates and products are involved. The impact of local reaction media and partitioning of reaction participants is a key area for further study, with importance both for understanding evolutionary advantages of intracellular droplet formation and for taking advantage of these complex reaction media for biotechnology. By performing reactions in relatively simple two-phase media where partitioning data can be collected and kinetic performance for each reaction can be measured in the individual phases, it is possible to generate predictive models for kinetics in sequential reactions $[12,13]$. More work in this area is needed to better understand the consequences of LLPS for biochemical reactions.

\section{Dynamic phase separation and compartmentalization in vitro and in vivo}

One of the most striking properties of intracellular membraneless organelles is their ability to form and disappear as needed during the life cycle of the cell. Solutes that have been 
compartmentalized by partitioning can be released to diffuse throughout the entire volume by converting to a single-phase system. Given the ability of these liquid organelles to localize active biomolecules and biochemical processes, their presence and absence provides a regulatory mechanism for cellular processes. Recapitulating this dynamic phase behavior outside of living cells is of great interest both for understanding its consequence for living systems and in order to take advantage of it as a regulatory mechanism for turning on and off nonbiological reactions.

In contrast, when phase separation persists and becomes irreversible, it is often detrimental to the cell and has been associated with disease states. For example, FUS is an RNA binding protein that contains low complexity domains (LCDs) and forms liquid droplets [31, 93]. In the liquid state, the protein retains disordered secondary structure, which allows for formation of transient interactions [93]. However, when droplets "age" (i.e. phase separation persists for a few hours), solid aggregate structures are formed [31]. Solid aggregates of FUS protein are also found in patients with ALS. Other studies have reported the deleterious effects of phase separation that persists, causing amyloid-like fibrillization/aggregation which is typically irreversible [27-30, 54]. In this review, we will focus on the reversible cases.

\subsection{Reversible compartmentalization initiated by changes to the solution conditions.}

In solutions of synthetic polymers or purified biomolecules, changes in solution conditions are a straightforward means of inducing a phase transition. Many phase systems are sensitive to changes in temperature, ionic strength, or $\mathrm{pH}$.

3.1.1 Thermal phase transitions. Phase transitions can often be induced by changes in temperature. Thermoresponsive polymers are well characterized, and many examples have 
appeared in the literature. For a review see [94]. A single polymer can either have a lower critical solution temperature (LCST) where the polymer is completely soluble at lower temperature and phase separation is observed upon heating, or the polymer can display an upper critical solution temperature (UCST), where the polymer is completely soluble at high temperature and the phase separation is observed upon cooling. The thermodynamics of these processes are described elsewhere $[94,95]$. Generally, for LCST polymers at low temperatures, the polymer interacts favorably with water. Upon heating, water-polymer interactions are weakened, and favorable intra- and intermolecular interactions of the polymer dominate. The entropy increases, from the release of once polymer-bound water molecules [94]. For a UCST polymer, the favorable polymer-polymer and solvent-solvent interactions occur a low temperature. Increasing temperature decreases the strength of the interactions, meaning the process is enthalpy driven [96].

Temperature responsive phase behavior has been observed for protein constructs of Ddx4 [20]. When fluorescently-labeled $\operatorname{Ddx} 4\left(\mathrm{Ddx} 4^{\mathrm{YFP}}\right)$ was expressed inside HeLa cells, droplet formation in vivo was strongly temperature dependent; at low expression levels, no droplets were observed. However, when the cells were temperature shocked at $2{ }^{\circ} \mathrm{C}$, droplets formed. Heating caused a decrease in volume and total number of granules and dispersal of Ddx4 into the nucleoplasm. This strong temperature dependence was also observed in vitro. A variant of Ddx4 that only contained the $\mathrm{N}$-terminal disordered region $\left(\mathrm{Ddx} 4^{\mathrm{N} 1}\right)$ phase separated at physiological conditions $\left(37^{\circ} \mathrm{C}\right.$ and $150 \mathrm{mM}$ salt) to form droplets reminiscent of the intracellular organelles. In another set of experiments in which the temperature was cycled, the droplets could be reversibly formed at low temperatures and disassembled at higher temperatures (Figure 7) [20]. 


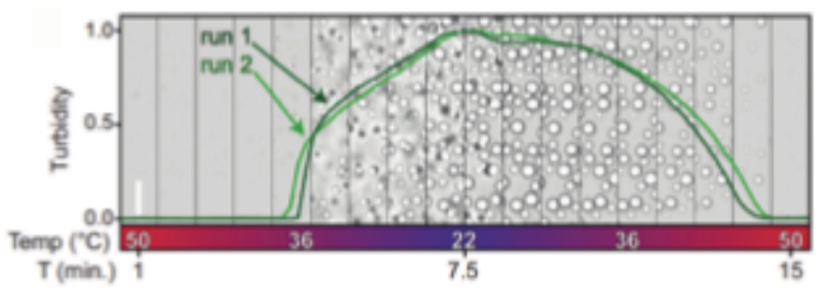

Figure 7. Temperature-dependence of an intrinsically-disordered protein associated with nuage. Bright-field microscopy images of $\mathrm{Ddx} 4^{\mathrm{N} 1}$ with varying temperature and time. Droplet formation occurred $<45^{\circ} \mathrm{C}$, and was fully reversible in a second cycle. The solution conditions were 202 $\mu \mathrm{M}$ protein, and $200 \mathrm{mM} \mathrm{NaCl}$. The scale bar is $50 \mu \mathrm{m}$. Adapted with permission from reference [20].

Recent work by Quiroz and Chilkoti provides design rules for peptide sequences with desired thermal properties, for example exhibiting either an LCST or UCST [97]. Inspired by the known thermally-responsive IDPs tropoelastin, collagen and resilin, these authors performed compositional analysis of Pro- and Gly-rich IDPs to identify candidate motifs capable of bestowing phase behavior to a scaffold rich in these residues. Experimental testing of the resulting repeat sequences indicated that intrinsically-disordered protein polymers could indeed be designed to exhibit thermal phase transitions over a wide range of conditions [97]. Other work has found that above a threshold of Pro and Gly content in peptides, amyloid formation can be impeded due to the increased hydration and disorder of the backbone [98]. Perry et al. found that chirality played a significant role in the morphology of poly(lysine)/poly(glutamic acid) complexes; fluid complexes formed when the polypeptides were racemic (due to disruption of hydrogen bonding), while chiral polypeptides made fibrillar solids with $\beta$-sheet structures [99]. Such work is an important step towards both understanding how phase behavior is encoded in the amino acid sequences of proteins and peptides and designing desired peptide materials for nonbiological applications [97-99]. 
Neutral polymer ATPS can also exhibit temperature-dependent phase behavior. For example certain compositions of the PEG/dextran system can be converted to a single phase by heating slightly above room temperature. Subsequent cooling can cause the system to phase separate. Our lab has used this phase behavior to encapsulate PEG/dextran ATPS inside giant lipid vesicles as illustrated in Figure 8A. Once the two-phase polymer solution has been encapsulated, it can be transitioned between one and two phases by changes in temperature, resulting in control over localization of any biomolecules that are partitioned between the phases. In Figure 8B, a fluorescently-tagged protein is localized into the dextran-rich phase. Upon heating, the phase boundary disappears and the protein is released throughout the vesicle interior; subsequent cooling results in phase separation and re-localization of the protein to the dextranrich phase droplet [100] Simple experimental model systems of this type capture key components of the intracellular membraneless organelles. Although this example converts from two phases at low temperature to one phase at high temperature, Long observed intriguing behavior for a different composition of PEG/dextran ATPS inside giant lipid vesicles. A single phase present at $25{ }^{\circ} \mathrm{C}$, converted to two phases when heated to $48{ }^{\circ} \mathrm{C}$ [101]. Such systems can begin serving as a simple model of the intracellular liquid organelle formation that occurs in response to heat stress $[4,31,102]$. 

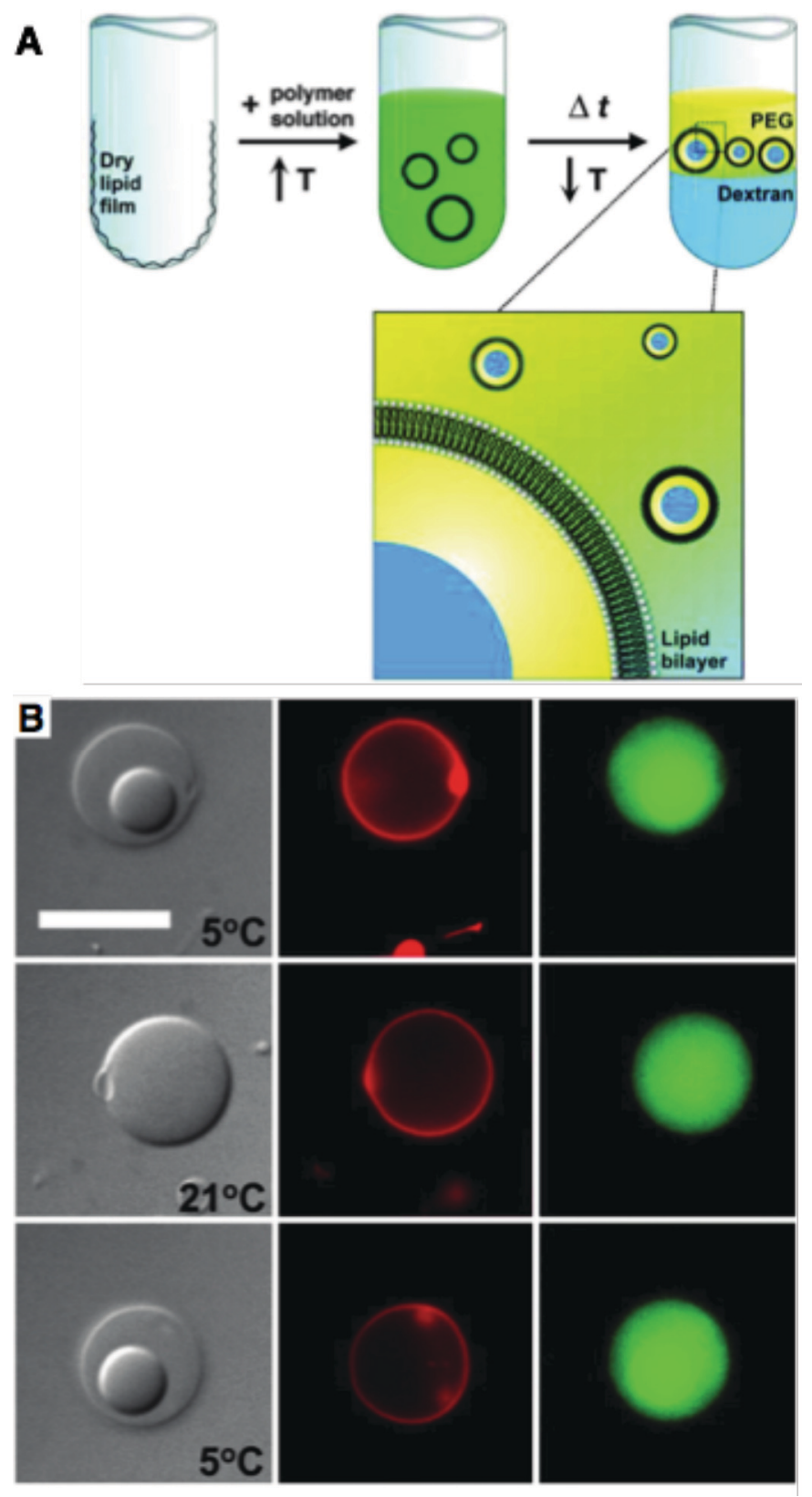

Figure 8. Temperature-induced phase separation and subsequent protein partitioning of a PEG/ dextran aqueous two-phase system in a lipid vesicle. (A) To prepare the vesicles, lipid films are dried inside of a test tube, and a warm solution of PEG and dextran polymers that is one phase is subsequently added. Upon cooling, phase separation will occur in the bulk, and within formed lipid vesicles. (B) The lipid vesicles can reversibly compartmentalize lectin-SBA protein to the dextran-rich phase (smaller phase) by changes in temperature. DIC (left), membrane fluorescence (center) and protein lectin SBA fluorescence (right) images The scale bar is $10 \mu \mathrm{m}$. Adapted with permission from reference [100]. 
3.1.2 Salt induced transitions. When LLPS involves electrostatic interactions between components, solution ionic strength can be used to tune the phase behavior. A routine analysis of coacervates is to determine the salt stability. At a certain concentration of salt, coacervates will dissolve due to loss of the entropic driving force from the release of polyelectrolyte-bound counterions. The stronger the interaction between the polyelectrolyte(s), the more salt will be needed to dissolve the coacervates. For biological coacervates, it is common to report the stability of the coacervate at physiological salt $(150 \mathrm{mM})$ to comment on the feasibility of such coacervates occurring inside the cell. Critical salt concentration can be increased by a number of means, such as increasing chain length, increasing charge density, and addition of other polyelectrolytes $[44,52,56]$. For example, in our system with poly $\mathrm{U}$ and peptide with sequence RRASLRRASL, the coacervates were stable up to a combined HEPES buffer and $\mathrm{NaCl}$ concentration of $100 \mathrm{mM}$. Addition of another RRASL repeat to form poly U/triple RRASL coacervates increased the stability to a combined $350 \mathrm{mM}$ total salt, and lowered the critical coacervate concentration from $250 \mu \mathrm{M}$ to $100 \mu \mathrm{M}$ peptide. [55]. Before reaching the critical salt concentration, addition of salt can increase the volume of the coacervate. For example, Wang and Schlenoff showed that increasing $\mathrm{KBr}$ concentration with poly(styrenesulfonate) (PSS) / poly(diallyldimethylammonium (PDADMA) coacervates caused an increase in the volume of the phase, going from a solid-like structure, to a liquid coacervate, and eventually to a single phase solution (Figure 9A and B) In another example, gelatine/gum Arabic coacervate droplet size increased with increasing salt concentration (Figure 9C). Removal of the salt caused the droplets to shrink to their original size. The process was reversible for at least three cycles [103]. 
A

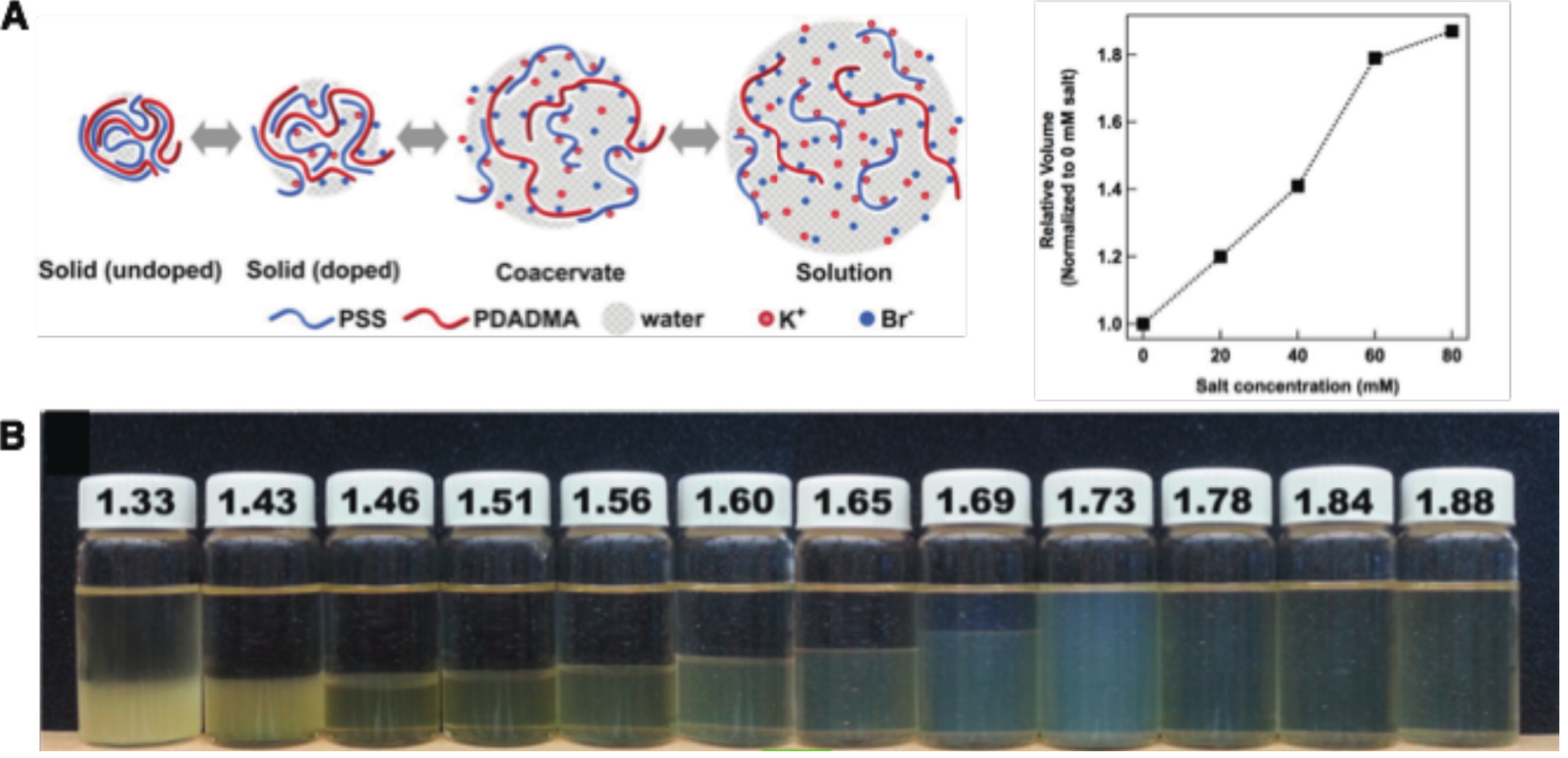

Figure 9. Effect of ionic strength on phase behavior for coacervates. (A) Scheme showing the effect of increasing salt on ion pairing and coacervate phase volume. (B) Volume increase with increasing ionic strength of gelatine/gum Arabic coacervates as a function of $\mathrm{KCl}$ concentration, plotted from diameter data reported in reference [103] (C) Volume increase of PSS/PDADMA coacervates. The $[\mathrm{KBr}]$ is indicated on each sample. The coacervates phase dissolved at $[\mathrm{KBr}]>$ 1.80 M. Panels A and B are reproduced with permission from reference [104] Copyright 2014, American Chemical Society.

3.1.3 pH-driven phase transitions. For polymers with weakly acidic or basic chemical groups, changes in $\mathrm{pH}$ can be used to alter protonation states, impacting electrostatic interactions. An example from Mann and coworkers demonstrating assembly and disassembly of poly(lysine) and nucleotide coacervates by changing the $\mathrm{pH}$ is shown in Figure 10. At $\mathrm{pH} 12.5$, the solution is transparent because the polylysine is near neutral (the $\mathrm{pK}_{\mathrm{a}}$ of the lysine amino side chain is 10.5). By lowering the $\mathrm{pH}$ to 7.2 with $\mathrm{CO}_{2}$ gas (middle panel) the polylysine is positively charged and can coacervate with the negatively charged nucleotide. Addition of $\mathrm{NH}_{3}$ gas increases the $\mathrm{pH}$ once again, and the coacervates dissolve. This was reversible and could be carried out for many cycles [7]. There are many other reported examples where changes in $\mathrm{pH}$ impact coacervate 
formation, including those with biomacromolecular components [105-108]. Changes in $\mathrm{pH}$ can be less dramatic, just changing the volume of the coacervate phase rather than completely dissolving it [105]. The $\mathrm{pH}$ can also be tuned so that the polyelectrolytes are charge-matched (1:1) to create a maximal volume coacervate phase [43].

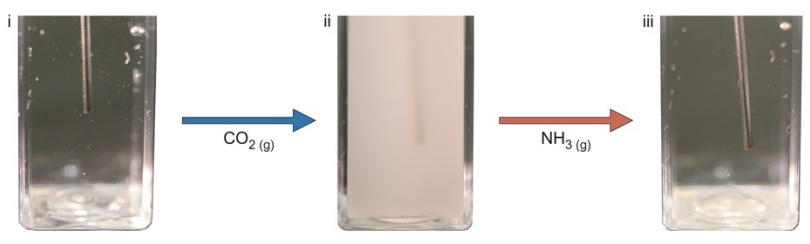

Figure 10. Changes in solution $\mathrm{pH}$ causes assembly and disassembly of polylysine/ATP coacervate droplets. At high $\mathrm{pH}$, the solution is transparent (left panel). Lowering of the $\mathrm{pH}$ by addition of $\mathrm{CO}_{2}$ gas causes droplet formation (center panel). Subsequence addition of $\mathrm{NH}_{3}$ causes dissolution of the coacervate (right panel). Adapted with permission from Macmillan Publishers Ltd., Nature Chemistry reference [7], copyright 2011.

\subsection{Reversible compartmentalization initiated by changes in concentration of phase-}

\section{forming macromolecules.}

As discussed above, there are a number of means by which phase separation can be controlled dynamically in a laboratory setting, but nearly all of these methods are incompatible with the interior of living cells, which generally must avoid even modest changes in temperature, $\mathrm{pH}$, ionic strength, and osmolality. Nonetheless intracellular membraneless organelles are known to appear and disappear at different times in the cell cycle. Intracellular changes in the local concentration of biomolecules needed to drive phase separation is feasible, for example by translation to form more of a protein or by biochemical degradation to reduce its concentration. 
A number of notable recent examples reporting on the effects of component concentration have been reported involving proteins that constitute liquid organelles. One is the protein known as Whi3, which is found in liquid organelles in the cytoplasm of the fungus Ashbya gossypii. The protein is disordered, containing a region rich in glutamine residues, known as polyQ tract. In vitro, the protein can form liquid droplets capable of coalescence at low salt $(75 \mathrm{mM})$ and high protein concentration $(28 \mu \mathrm{M})$. Smaller droplets formed at concentrations from 1-16 $\mu \mathrm{M}$ do not coalesce. Although the phase separation of this protein alone was not stable at physiological salt, it could be induced by addition of $C L N 3$, an mRNA that binds to the RNA recognition motif of Whi3. The presence of the RNA lowered the critical concentration to $200 \mathrm{nM}$ [30]. In another example, the protein LAF-1, which is found in C. elegans $\mathrm{P}$ granules, phase separates in vitro. The critical protein concentration was $800 \mathrm{nM}$ at $125 \mathrm{mM} \mathrm{NaCl}$, which is the same order of magnitude of the estimated intracellular concentration. The phase behavior could be tuned by changes in the salt concentration. The $\mathrm{N}$ terminal disordered region of the protein alone, which contains arginine/glycine motifs, was necessary and sufficient to form the phase droplets [19]. In vivo, Weber and Brangwynne found an inverse size scaling of the nucleolus when C. elegans embroyo size was altered. Their observations point to a reduced ability to form nucleoli by phase separation when the concentration of nucleolar components was reduced by the increased nuclear volume [109]. This in vivo example supports a role for intracellular concentration in formation of membraneless organelles by LLPS.

It should be noted that most factors important for LLPS are not independent. The concentration of phase-forming polymer required for droplet formation can depend on solution temperature, ionic strength, $\mathrm{pH}$, and/or the presence of other molecules (e.g., RNAs). For 
example, Figure 11 illustrates the interconnectedness of temperature, concentration, and temperature on the phase formation of $\mathrm{Ddx} 4^{\mathrm{N} 1}$ [20]. At higher concentrations of protein and lower salt, droplets were more stable at elevated temperature. LAF-1 has been shown to form droplets at higher salt concentrations when the protein is more concentrated [19].

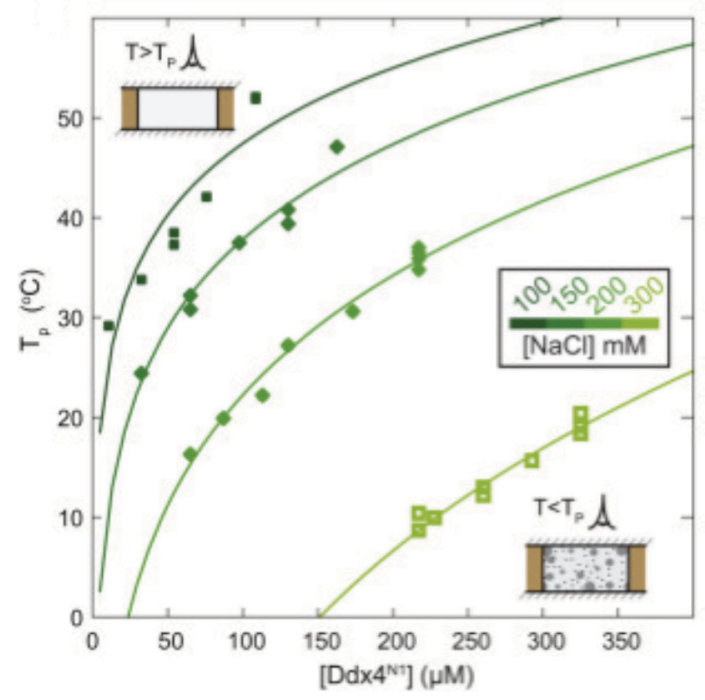

Figure 11. A phase diagram of $\mathrm{Ddx} 4^{\mathrm{N} 1}$ phase separation as function of concentration, temperature, and salt concentration at $\mathrm{pH}$ 8. Areas below each line are 2 phases, and areas above each line are 1 phase. The experiment data is the points, and the lines are modeling fits based on the Flory-Huggins model of phase separation. Reproduced with permission from reference [20].

Polymer concentration also plays an important role in synthetic polymer systems. Neutral polymer systems are generally more sensitive to concentration than complex coacervates, particularly when the latter are formed from polyions that have a high degree of multivalency. For example, in poly(acrylic acid)/poly(allylamine) systems, coacervation occurs below $0.1 \mathrm{wt} \%$ total polymer [45]. In contrast, neutral polymer systems generally require at least several weight percent of total polymer for phase separation [34]. For a complex coacervate system, the relative concentrations of oppositely charged functional groups are important. The degree of phase 
separation in terms of turbidity can be tuned by changing the relative concentration of the oppositely-charged polyelectrolytes. Holding one polyelectrolyte constant, maximum turbidity is reached when the coacervates are charged matched. As one example, Priftis and Tirrell showed this for a set of poly(lysine)/poly(glutamic acid) peptides [44].

When a polymer solution is encapsulated by a semipermeable membrane, such as the lipid bilayer of a giant vesicle, it is possible to change its concentration using external osmotic pressure. By adding osmolytes (e.g., sucrose) to the external solution, the lipid vesicle's volume is decreased, concentrating the polymers on the inside. This can drive phase separation and has further been used to increase interfacial tension at the aqueous/aqueous phase boundary and to drive wetting transitions and partial or complete vesicle budding [8, 110-112]. This method has been used for synthetic neutral polymer systems (PEG/dextran). A related approach, where water was osmotically removed from droplets of cell lysate in oil, has been used to drive phase separation in bacterial cell lysates, resulting in increased transcription rate [9].

\subsection{Reversible compartmentalization initiated by post-translational modifications of proteins}

In addition to changes in concentration of phase-forming macromolecules as described in the previous section, another biological mechanism that is extremely plausible is the use of posttranslational modifications to change the phase behavior of biomacromolecules without altering their concentration. In this section, we introduce several relevant types of post-translational modifications and their known or potential roles in determining phase separation, with a special emphasis on phosphorylation. 


\subsubsection{Phosphoregulation of coacervate formation}

Phosphorylation is a reversible post-translational modification that plays an important regulatory role in a number of processes by controlling protein structure and enzyme activity. Recent work has implicated phosphorylation as a key determinant in membraneless organelle assembly. A notable example is the work of Seydoux and coworkers which has demonstrated the regulation of $\mathrm{P}$ granule (dis)assembly by phosphorylation. Marker proteins for $\mathrm{P}$ granules that have intrinsically disordered regions were found to be substrates for a kinase/phosphatase pair. Kinase activity caused disassembly of the $\mathrm{P}$ granules, while phosphatase activity had the opposite effect [113]. Other reports have suggested the importance of phosphorylation for controlling compartment formation $[25,26,82]$.

We recently demonstrated that phosphorylation is a viable means to control coacervate formation and dissolution. This was done using the using the poly U/RRASLRRASL system. The peptide sequence was inspired by the peptide Kemptide, which is a model synthetic substrate for the enzyme protein kinase A (PKA). The four Arg residues make it highly positively charged $(\mathrm{pI}=12.5)$ and the Ser residues are phosphorylation sites. Looking at the phosphorylation strictly from an electrostatic point of view, the addition of a phosphate group to a peptide will decrease the net charge of the peptide by 2 . In the case of RRASLRRASL, the charge will decrease from approximately +4 to 0 , and changing the $\mathrm{pI}$ to 7.6 . Therefore, we anticipated that addition of phosphates to the peptide would inhibit phase separation because the peptide would become neutrally charged at neutral $\mathrm{pH}$. That is exactly what we observed - no phase separation occurred with singly or doubly phosphorylated peptide. 
Biology carries out phosphorylation using enzymes - kinases and phosphatases. With our minimalist system, we used protein kinase A (PKA) and lambda protein phosphatase (LPP) to carry out the addition and removal of phosphates, respectively from the peptide (Figure 12A). Starting with doubly phosphorylated substrate, RRApSLRRApSL. LPP acted on the substrate to produce RRASLRRASL, which is necessary for phase separation. The LPP activity resulted in coacervate formation, as shown in Figure 12B. This process was completely reversible. The polyU/RRASLRRASL droplets disassembled with the addition of PKA and ATP. We even demonstrated that reversibility could be achieved in the same coacervate solution by modulation of the opposing kinase and phosphatase activities as a function of time. LPP-induced coacervate formation could be controlled with the addition/removal of $\mathrm{Mn}^{2+}$, as LPP is a manganese dependent phosphatase. Similarly, kinase could be controlled by the presence of ATP, and it could be replenished to reactivate the kinase, and cause coacervate disassembly. This process was reversible for 2 cycles for each enzyme (Figure 12C). The corresponding turbidity graph shows that phase separation occurs as a result of LPP activity, and conversely, the solution becomes one phase with kinase activity (Figure 12D). We further characterized the system by monitoring the concentration of all the peptide species as a function of time - which indicates that phase separation did not occur when RRASLRRASL was below the critical concentration range of 200-250 $\mu \mathrm{M}$ (black trace in Figure 12E). 


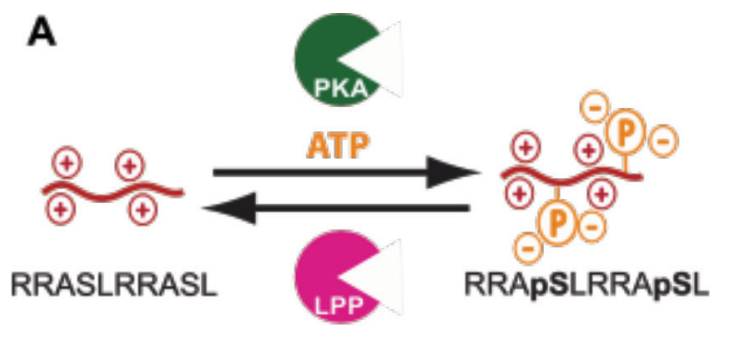

B
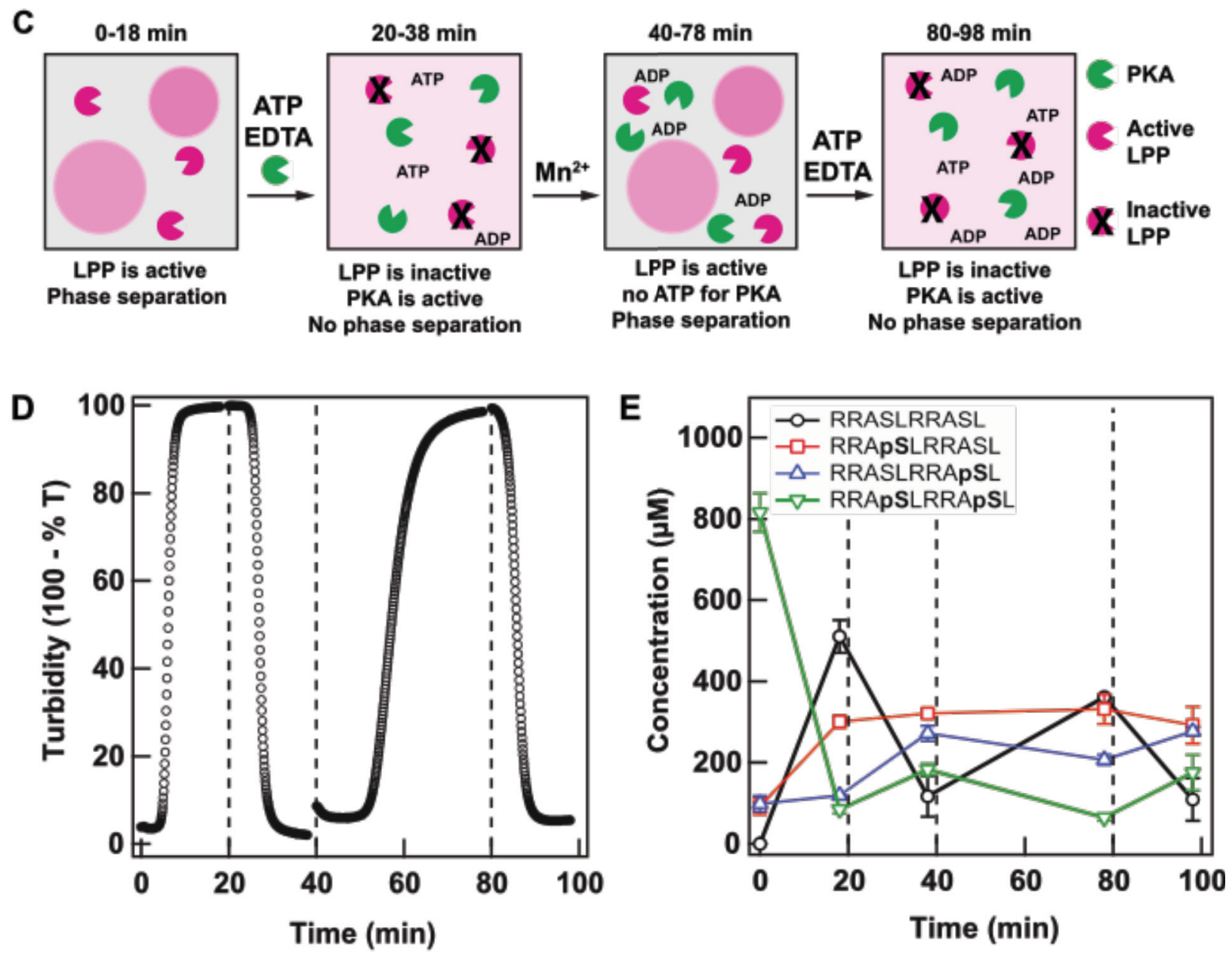

Figure 12. Dynamic control of RNA/peptide complex coacervation using phosphorylation. (A) Schematic representation of the enzyme activities on the peptide substrates, RRASLRRASL and RRApSLRRApSL. Kinase activity requires ATP as a source of inorganic phosphate. (B) Kinase activity causes droplet disassembly, while phosphatase activity results in droplet formation. (C) Schematic illustration of changes in enzyme activity and their effects on coacervation. From 0-18 minutes, LPP is active and phase separation occurs. At 20 minutes, EDTA is added to complex $\mathrm{Mn}^{2+}$ and stop LPP activity. Kinase and ATP are added, and phase separation no longer occurs. From 40 minutes, addition of more $\mathrm{Mn}^{2+}$ reactivates the phosphatase and phase separation occurs again. Finally, at 80 minutes, more EDTA and ATP are added, and the kinase and the coacervate phase dissolves again. (D) Turbidity graph corresponding to the solution conditions outlined in 
part (C). (E) Concentration of each of the peptides as a function of time. Phase separation requires that RRASLRRASL concentration is greater than $\sim 250 \mu \mathrm{M}$. Figure adapted with permission from Macmillan Publishers Ltd: Nature Chemistry [55] copyright 2016.

\subsubsection{Other post-translational modifications}

Although phosphorylation is perhaps the most obvious post-translational modification (PTM) to change the charge and consequently phase behavior of a protein, it is not the only viable candidate. Intracellular functions of IDPs are modulated by multiple types of posttranslational modifications [114]. Chemical groups added by PTM include not only phosphoryl, but also alkyl, glycosyl or acyl groups or even small proteins (e.g., ubiquitin, small ubiquitin-like

modifier [SUMO]). For example, formation of the nuage is correlated with the arginine methylation state of Ddx4. The enzymatic addition of two methyl groups at arginine residues within RGG motifs on the Ddx4 construct destabilized the droplets, causing them to dissolve at a lower salt concentration than non-methylated Ddx4 construct droplets [20]. These PTMs therefore present appealing targets for generating experimental models for enzyme-responsive droplet formation similar to the polyU/peptide phosphorylation system described above.

\section{Concluding thoughts}

This is an exciting time to be studying aqueous multiphase systems. With LLPS only recently appreciated in Biology and countless questions remaining as to the role of this phenomenon in cellular functions, applying physical-chemical approaches to such systems is of great importance. In addition to studies using live cells and purified proteins known to exist in membraneless organelles, studies of entirely synthetic, nonbiological polymers can also help shed light on the underlying mechanisms and possible (nonbiological) applications of 
localization by LLPS. Using a combination of approaches and molecular types, it is possible to evaluate hypotheses for how biomolecule-rich droplets form and what their properties and roles are in cellular functions. Beyond this, by better understanding how to control dynamic formation and disappearance of these structures, new applications in fields as diverse as drug delivery, catalysis and materials fabrication could be enabled.

\section{Acknowledgements}

The authors acknowledge support from the National Science Foundation, grant no.

MCB-1244180.

\section{References}

[1] Brangwynne CP. Soft Matter 2011;7:3052-9.

[2] Kasza KE, Rowat AC, Liu JY, Angelini TE, Brangwynne CP, Koenderink GH, Weitz DA. Curr Opin Cell Biol 2007;19:101-7.

[3] Hyman AA, Weber CA, Juelicher F. Annu Rev Cell Dev Biol 2014;30:39-58.

[4] Mitrea DM, Kriwacki RW. Cell Commun Signal 2016;14.

[5] Keating CD. Acc Chem Res 2012;45:2114-24.

[6] Williams DS, Koga S, Hak CRC, Majrekar A, Patil AJ, Perriman AW, Mann S. Soft Matter 2012;8:6004-14.

[7] Koga S, Williams DS, Perriman AW, Mann S. Nat Chem 2011;3:720-4.

[8] Dimova R, Lipowsky R. Soft Matter 2012;8:6409-15.

[9] Sokolova E, Spruijt E, Hansen MMK, Dubuc E, Groen J, Chokkalingam V, Piruska A, Heus HA, Huck WTS. Proc Natl Acad Sci USA 2013;110:11692-7.

[10] Torre P, Keating CD, Mansy SS. Langmuir 2014;30:5695-9.

[11] Tang TYD, van Swaay D, deMello A, Anderson JLR, Mann S. Chem Commun 2015;51:11429-32.

[12] Aumiller WM, Davis BW, Hashemian N, Maranas C, Armaou A, Keating CD. J Phys Chem B 2014;118:2506-17.

[13] Davis BW, Aumiller WM, Hashemian N, An S, Armaou A, Keating CD. Biophys J 2015;109:2182-94.

[14] Strulson CA, Molden RC, Keating CD, Bevilacqua PC. Nat Chem 2012;4:941-6.

[15] Alberts B. Molecular Biology of the Cell. New York: Garland Science; 2008.

[16] Lehninger AL, Nelson DL, Cox MM. Lehninger Principles of Biochemistry. New York:

W.H. Freeman; 2013. 
[17] Cornejo E, Abreu N, Komeili A. Curr Opin Cell Biol 2014;26:132-8.

[18] Vendeville A, Lariviere D, Fourmentin E. FEMS Microbiol Rev 2011;35:395-414.

[19] Elbaum-Garfinkle S, Kim Y, Szczepaniak K, Chen CCH, Eckmann CR, Myong S, Brangwynne CP. Proc Natl Acad Sci USA 2015;112:7189-94.

[20] Nott TJ, Petsalaki E, Farber P, Jervis D, Fussner E, Plochowietz A, Craggs TD, Bazett-Jones DP, Pawson T, Forman-Kay JD, Baldwin AJ. Mol Cell 2015;57:936-47.

[21] Brangwynne CP, Eckmann CR, Courson DS, Rybarska A, Hoege C, Gharakhani J, Jülicher F, Hyman AA. Science 2009;324:1729-32.

[22] Brangwynne CP, Mitchison TJ, Hyman AA. Proc Natl Acad Sci USA 2011;108:4334-9.

[23] Hancock R, Jeon KW, (editors). New Models of the Cell Nucleus: Crowding, Entropic

Forces, Phase Separation, and Fractals 2014;307:1-496.

[24] Berry J, Weber SC, Vaidya N, Haataja M, Brangwynne CP. Proc Natl Acad Sci USA 2015;112:E5237-E45.

[25] Li P, Banjade S, Cheng H-C, Kim S, Chen B, Guo L, Llaguno M, Hollingsworth JV, King

DS, Banani SF, Russo PS, Jiang Q-X, Nixon BT, Rosen MK. Nature 2012;483:336-40.

[26] Wippich F, Bodenmiller B, Trajkovska MG, Wanka S, Aebersold R, Pelkmans L. Cell 2013;152:791-805.

[27] Molliex A, Temirov J, Lee J, Coughlin M, Kanagaraj AP, Kim HJ, Mittag T, Taylor JP. Cell 2015;163:123-33.

[28] Lin Y, Protter DSW, Rosen MK, Parker R. Mol Cell 2015;60:208-19.

[29] Altmeyer M, Neelsen KJ, Teloni F, Pozdnyakova I, Pellegrino S, Grofte M, Rask MBD, Streicher W, Jungmichel S, Nielsen ML, Lukas J. Nat Commun 2015;6.

[30] Zhang HY, Elbaum-Garfinkle S, Langdon EM, Taylor N, Occhipinti P, Bridges AA, Brangwynne CP, Gladfelter AS. Mol Cell 2015;60:220-30.

[31] Patel A, Lee HO, Jawerth L, Maharana S, Jahnel M, Hein MY, Stoynov S, Mahamid J, Saha S, Franzmann TM, Pozniakovski A, Poser I, Maghelli N, Royer LA, Weigert M, Myers EW, Grill S, Drechsel D, Hyman AA, Alberti S. Cell 2015;162:1066-77.

[32] Wohlfarth C. CRC handbook of phase equilibria and thermodynamic data of aqueous polymer solutions. Boca Raton, FL: Taylor \& Francis; 2013.

[33] de Kruif CG, Weinbreck F, de Vries R. Curr Opin Colloid Interface Sci 2004;9:340-9.

[34] Albertsson P-Å. Partition of Cell Particles and Macromolecules. New York: Wiley; 1986.

[35] Aumiller WM, Davis BW, Keating CD. Int Rev Cell Mol Biol 2014;307:109-49.

[36] Zaslavsky BY. Aqueous two-phase partitioning: physical chemistry and bioanalytical applications. New York: M. Dekker; 1995.

[37] Fu JC, Schlenoff JB. J Am Chem Soc 2016;138:980-90.

[38] Bungenberg de Jong HG. Colloid science Kruyt HR (editor). Vol. 2. Amsterdam: Elsevier; 1949.

[39] Leong KW, Mao HQ, Truong-Le VL, Roy K, Walsh SM, August JT. J Control Release 1998;53:183-93.

[40] Ohsugi A, Furukawa H, Kakugo A, Osada Y, Gong JP. Macromol Rapid Commun 2006;27:1242-6.

[41] Evreinova TN, Karnaukhov WN, Mamontova TW, Ivanizki GR. J Colloid Interface Sci 1971;36:18-23. 
[42] Comert F, Malanowski AJ, Azarikia F, Dubin PL. Soft Matter 2016;12:4154-61.

[43] Perry SL, Li Y, Priftis D, Leon L, Tirrell M. Polymers 2014;6:1756-72.

[44] Priftis D, Tirrell M. Soft Matter 2012;8:9396-405.

[45] Chollakup R, Smitthipong W, Eisenbach CD, Tirrell M. Macromolecules 2010;43:2518-28.

[46] van der Gucht J, Spruijt E, Lemmers M, Stuart MAC. J Colloid Interface Sci

2011;361:407-22.

[47] Hatti-Kaul R. Aqueous two-phase systems: methods and protocols. Totowa, N.J.: Humana Press; 2000.

[48] Walter H, Brooks DE, Fisher D. Partitioning in aqueous two-phase systems: theory, methods, uses, and application to biotechnology. Orlando: Academic Press; 1985.

[49] Tolstoguzov V. Int Rev Cytol 2000;192:3-31.

[50] Albertsson PA, Birkenmeier G. Anal Biochem 1988;175:154-61.

[51] Hartman A, Johansson G, Albertsson P-A. Eur J Biochem 1974;46:75-81.

[52] Priftis D, Xia XX, Margossian KO, Perry SL, Leon L, Qin J, de Pablo JJ, Tirrell M.

Macromolecules 2014;47:3076-85.

[53] Uversky VN, Kuznetsova IM, Turoverov KK, Zaslavsky B. FEBS Lett 2015;589:15-22.

[54] Brangwynne CP, Tompa P, Pappu RV. Nat Phys 2015;11:899-904.

[55] Aumiller WM, Keating CD. Nat Chem 2016;8:129-37.

[56] Spruijt E, Westphal AH, Borst JW, Stuart MAC, van der Gucht J. Macromolecules

2010;43:6476-84.

[57] Strome S. Wormbook 2015:1-10.

[58] Ahmad Y, Boisvert FM, Gregor P, Cobley A, Lamond AI. Nucleic Acids Res

2009;37:D181-4.

[59] Priftis D, Farina R, Tirrell M. Langmuir 2012;28:8721-9.

[60] Spruijt E, Sprakel J, Stuart MAC, van der Gucht J. Soft Matter 2010;6:172-8.

[61] Forciniti D, Hall CK, Kula MR. J Biotechnol 1990;16:279-96.

[62] Liu YG, Lipowsky R, Dimova R. Langmuir 2012;28:3831-9.

[63] Feric M, Vaidya N, Harmon TS, Mitrea DM, Zhu L, Richardson TM, Kriwacki RW, Pappu

RV, Brangwynne CP. Cell 2016.

[64] Pickering SU. J Chem Soc 1907;91:2001-21.

[65] Aveyard R, Binks BP, Clint JH. Adv Colloid Interface Sci 2003;100:503-46.

[66] Dewey DC, Strulson CA, Cacace DN, Bevilacqua PC, Keating CD. Nat Commun 2014;5.

[67] Fothergill J, Li M, Davis SA, Cunningham JA, Mann S. Langmuir 2014;30:14591-6.

[68] Balakrishnan G, Nicolai T, Benyahia L, Durand D. Langmuir 2012;28:5921-6.

[69] Buzza DMA, Fletcher PDI, Georgiou TK, Ghasdian N. Langmuir 2013;29:14804-14.

[70] Mao YTS, Zhang B, Spector DL. Trends Genet 2011;27:295-306.

[71] Boisvert FM, van Koningsbruggen S, Navascues J, Lamond AI. Nature Reviews Molecular

Cell Biology 2007;8:574-85.

[72] Feric M, Brangwynne CP. Nat Cell Biol 2013;15:1253-9.

[73] Zhang Q, Kota KP, Alam SG, Nickerson JA, Dickinson RB, Lele TP. J Cell Physiol

2016;231:1269-75.

[74] Asenjo JA, Andrews BA. J Chromatogr A 2011;1218:8826-35.

[75] Frankel EA, Bevilacqua PC, Keating CD. Langmuir 2016;32:2041-9. 
[76] Nott TJ, Craggs TD, Baldwin AJ. Nat Chem 2016;8:569-75.

[77] Tang TYD, Antognozzi M, Vicary JA, Perriman AW, Mann S. Soft Matter 2013;9:7647-56.

[78] Di Nucci H, Nerli B, Pico G. Biophys Chem 2001;89:219-29.

[79] Dominak LM, Gundermann EL, Keating CD. Langmuir 2010;26:5697-705.

[80] Ubersax JA, Ferrell JE. Nat Rev Mol Cell Biol 2007;8:530-41.

[81] Johnson LN, Lewis RJ. Chem Rev 2001;101:2209-42.

[82] Dundr M. Curr Opin Cell Biol 2012;24:415-22.

[83] Schoffelen S, van Hest JCM. Soft Matter 2012;8:1736-46.

[84] Conrado RJ, Varner JD, DeLisa MP. Curr Opin Biotechnol 2008;19:492-9.

[85] Jia F, Narasimhan B, Mallapragada S. Biotechnol Bioeng 2014;111:209-22.

[86] Cacace DN, Keating CD. J Mat Chem B 2013;1:1794-803.

[87] Cacace DN, Rowland AT, Stapleton JJ, Dewey DC, Keating CD. Langmuir 2015;31:11329-38.

[88] Crosby J, Treadwell T, Hammerton M, Vasilakis K, Crump MP, Williams DS, Mann S. Chem Commun 2012;48:11832-4.

[89] Zhou HX, Rivas GN, Minton AP. Annu Rev Biophys 2008;37:375-97.

[90] Breydo L, Reddy KD, Piai A, Felli IC, Pierattelli R, Uversky VN. Biochim Biophys Acta, Proteins Proteomics 2014;1844:346-57.

[91] Aumiller WM, Davis BW, Hatzakis E, Keating CD. J Phys Chem B 2014;118:10624-32.

[92] Olsen SN. Thermochim Acta 2006;448:12-8.

[93] Burke KA, Janke AM, Rhine CL, Fawzi NL. Mol Cell 2015;60:231-41.

[94] Roy D, Brooks WLA, Sumerlin BS. Chem Soc Rev 2013;42:7214-43.

[95] Seuring J, Agarwal S. Macromol Rapid Commun 2012;33:1898-920.

[96] Seuring J, Agarwal S. ACS Macro Lett 2013;2:597-600.

[97] Quiroz FG, Chilkoti A. Nat Mater 2015;14:1164-71.

[98] Rauscher S, Baud S, Miao M, Keeley FW, Pomes R. Structure 2006;14:1667-76.

[99] Perry SL, Leon L, Hoffmann KQ, Kade MJ, Priftis D, Black KA, Wong D, Klein RA, Pierce

CF, Margossian KO, Whitmer JK, Qin J, de Pablo JJ, Tirrell M. Nat Commun 2015;6.

[100] Long MS, Jones CD, Helfrich MR, Mangeney-Slavin LK, Keating CD. Proc Natl Acad Sci USA 2005;102:5920-5.

[101] Long MS. Dynamic and asymmetric protein microcompartmentation in aqueous two-phase vesicles. Pennsylvania State University Doctoral Thesis; 2005.

[102] Wallace EWJ, Kear-Scott JL, Pilipenko EV, Schwartz MH, Laskowski PR, Rojek AE,

Katanski CD, Riback JA, Dion MF, Franks AM, Airoldi EM, Pan T, Budnik BA, Drummond DA. Cell 2015;162:1286-98.

[103] Bungenberg de Jong HG, Landsmeer JMF. Recl Trav Chim Pays-Bas 1946;65:606-13. [104] Wang QF, Schlenoff JB. Macromolecules 2014;47:3108-16.

[105] Burgess DJ, Carless JE. J Colloid Interface Sci 1984;98:1-8.

[106] Schmitt C, Sanchez C, Desobry-Banon S, Hardy J. Crit Rev Food Sci Nutr 1998;38:689-753.

[107] Kaibara K, Okazaki T, Bohidar HB, Dubin PL. Biomacromolecules 2000;1:100-7.

[108] Jha PK, Desai PS, Li JY, Larson RG. Polymers 2014;6:1414-36.

[109] Weber SC, Brangwynne CP. Curr Biol 2015;25:641-6. 
[110] Andes-Koback M, Keating CD. J Am Chem Soc 2011;133:9545-55.

[111] Li YH, Lipowsky R, Dimova R. J Am Chem Soc 2008;130:12252-3.

[112] Long MS, Cans A-S, Keating CD. J Am Chem Soc 2008;130:756-62.

[113] Wang JT, Smith J, Chen BC, Schmidt H, Rasoloson D, Paix A, Lambrus BG, Calidas D, Betzig E, Seydoux G. Elife 2014;3.

[114] Bah A, Forman-Kay JD. J Biol Chem 2016;291:6696-705. 